\title{
The Problem of Serial Order in Skilled Typing
}

\author{
Kristy M. Snyder and Gordon D. Logan \\ Vanderbilt University
}

\begin{abstract}
We address the problem of serial order in skilled typing, asking whether typists represent the identity and order of the keystrokes they type jointly by linking successive keystrokes into a chained sequence, or separately by associating keystrokes with position codes. In 4 experiments, typists prepared to type a prime word and were probed to type a target word. We varied the overlap between the identity and order of keystrokes in the prime and the target. Experiment 1 tested whether the identity of keystrokes can be primed separately from their order. Experiments 2 and 3 tested whether keystroke positions can be primed out of sequence. Experiment 4 tested whether keystrokes are primed equally across serial positions. The results were consistent with chaining theories: Keystroke identities were not primed separately from their order, keystroke positions were not primed out of sequence, and priming was graded across the keystroke sequence and depended on the number of keystrokes that were primed in sequence. We conclude by discussing the possibility that the problem of serial order may be solved differently for different sequential tasks.
\end{abstract}

Keywords: serial order, motor control, chaining, position coding, skill

Many of the tasks we accomplish every day require the execution of specific sequences of actions. To accomplish sequential tasks, the cognitive system must control the order in which the requisite actions are executed. How the cognitive system is able to accomplish such a feat is known as the problem of serial order (Lashley, 1951). Many psychologists have studied the problem of serial order in speech production (Dell, 1986, 1990; Levelt, 1989; Mackay, 1987; O’Seaghdha \& Marin, 2000; Sevald \& Dell, 1994; Stemberger, 1985, 1990) and serial recall (Botvinick \& Plaut, 2006; Brown, Preece, \& Hulme, 2000; Burgess \& Hitch, 1999; Conrad, 1965; Crossman, 1961; Estes, 1972; Grossberg, 1978; Hartley \& Houghton, 1996; Healy, 1974; Henson, 1998; Lee \& Estes, 1977, 1981; Melton \& Irwin, 1940; Murdock, 1983; Page \& Norris, 1998; Wickelgren, 1965). These studies typically contrast two classic theoretical perspectives: chaining and position coding. Most of this work suggests that the cognitive system solves the problem of serial order with position coding rather than chaining (but see Botvinick \& Plaut, 2006).

The purpose of the present study is to test the generality of this conclusion by investigating the problem of serial order in skilled typing. Typing is an important test case for generalization because it is ubiquitous in the modern world. It is the gateway to computer literacy. Most college students are expert typists, typing as quickly and accurately as the professional typists of yesteryear (50-100 words per minute [WPM]; Logan \& Crump, 2011). Successful generalization would expand the scope of position coding theories

This article was published Online First June 30, 2014.

Kristy M. Snyder and Gordon D. Logan, Department of Psychology, Vanderbilt University.

Correspondence concerning this article should be addressed to Kristy M. Snyder, Department of Psychology, Vanderbilt University, 111 21st Avenue South, Wilson Hall 631, Nashville, TN, 37240. E-mail: kristy.m .snyder@vanderbilt.edu to an important new task with billions of practitioners. A failure to generalize would be a significant exception to the rule and a significant boost for serial chaining theories.

\section{The Problem of Serial Order: One Problem or Many?}

Studies of serial order often seem to assume that all sequential behaviors pose the same problem. However, complex behaviors like speaking may pose at least two problems of serial order. One problem is maintaining an explicit representation of a novel but linguistically structured sequence of words in short-term memory (STM). The other problem is maintaining an implicit representation of well-learned sequences of speech movements in a motor buffer. The nature of the representations and the mechanisms that maintain them differ, so the mechanisms that solve the problem of serial order in STM and in motor control may differ as well.

Skilled typing is similar to speaking, in that it also requires the maintenance of serial order information in STM and in a motor buffer. For both tasks, the problem of serial order in STM is to maintain a sequence of linguistically structured words, so the cognitive system is likely to solve this problem in the same way. For both tasks, the problem of serial order in the motor buffer is to maintain a sequence of well-learned actions. However, the actions in speech require the coordination of the lips, tongue, jaw, and larynx to express phonemes and produce sounds. The actions in typing require the bimanual coordination of eight fingers to express letters and produce visual shapes on a computer screen. The effectors, actions, and intended outcomes differ, so the mechanisms that solve the problem of serial order may differ as well.

\section{Theories of Serial Order}

Classic chaining theories assume that serial order is represented by a chain of directional associations between successive items (Washburn, 1916). Each link in the chain connects two items or actions. Sequences are produced in the correct serial order because 
each item serves as the cue that retrieves the item that follows it. Modern chaining theories assume that serial order is represented by compound associations between prior items in a sequence and the context (Botvinick \& Plaut, 2004, 2006; Chance \& Kahana, 1997; Keele, Ivry, Mayr, Hazeltine, \& Heuer, 2003; Murdock, 1993; Yamashita \& Tani, 2008). Sequences are produced in the correct serial order because the prior items and context serve as the cues that retrieve the next item. Chaining theories represent item and order information jointly: Each link in the chain represents an item and the sequence of links represents serial order.

Classic position coding theories assume that serial order is represented by associating items with ordinal position codes (Conrad, 1965; Crossman, 1961). Items are not associated directly with each other. Rather, they are associated directly with position codes, and each position code is associated with the next one in the sequence. Modern position coding theories assume that the order of the position codes is represented by a magnitude representation or by a gradient of activation called a primacy gradient (Brown et al., 2000; Bullock \& Rhodes, 2003; Burgess \& Hitch, 1999; Crowder, 1982; Glenberg \& Swanson, 1986; Grossberg, 1978; Hartley \& Houghton, 1996; Murdock, 1960; Page \& Norris, 1998; Rhodes, Bullock, Verwey, Averbeck, \& Page, 2004). Sequences are produced by stepping through the position codes in serial order, retrieving, and then producing the item associated with each position code. Position coding theories assume that item and order are represented separately: Each position code provides a "slot" that is temporarily filled by an item and the sequence of position codes is used to control serial order.

\section{Serial Order and Errors}

Psychologists have used many strategies in their quest to understand how the cognitive system solves the problem of serial order. One of these strategies is to examine tasks like serial recall, in which a failure to maintain sequential information results in errors. Serial recall tasks are commonly used to study serial order in STM (Botvinick \& Plaut, 2006; Brown et al., 2000; Burgess \& Hitch, 1999; Conrad, 1965; Crossman, 1961; Estes, 1972; Grossberg, 1978; Hartley \& Houghton, 1996; Healy, 1974; Henson, 1998; Lee \& Estes, 1977, 1981; Melton \& Irwin, 1940; Murdock, 1983; Page \& Norris, 1998; Wickelgren, 1965). Serial recall tasks require subjects to recall lists of verbal items in the order in which they were presented. When order information is not maintained properly, transposition errors occur, resulting in exchanges of adjacent items or exchanges of nonadjacent items that occupy equivalent positions. Item information is often lost in these tasks, resulting in omission and insertion errors.

Lashley (1951) claimed that classic chaining theories are unable to account for transpositions. Classic chaining theories assume that each item serves as the cue for the subsequent item, so items within a sequence cannot be exchanged (adjacent transpositions) and items from different sequences cannot be exchanged (nonadjacent transpositions).

Position coding theories were then proposed as an alternative to classic chaining theories (Brown et al., 2000; Bullock \& Rhodes, 2003; Burgess \& Hitch, 1999; Conrad, 1965; Crossman, 1961; Crowder, 1982; Glenberg \& Swanson, 1986; Grossberg, 1978; Hartley \& Houghton, 1996; Murdock, 1960; Page \& Norris, 1998; Rhodes et al., 2004). Position coding theories account for trans- positions by assuming that items are temporarily associated with position codes, so noise in the system can cue an item associated with a different position code within the sequence (adjacent transpositions) or cue an item associated with the same position code from another sequence (nonadjacent transpositions).

Psychologists then proposed extensions to chaining theory to account for transpositions (Botvinick \& Plaut, 2004, 2006; Chance \& Kahana, 1997; Keele et al., 2003; Murdock, 1993; Yamashita \& Tani, 2008). Modern chaining theories assume that compound associations among all prior items and the context cue each successive item in the sequence, so the compound associations can cue items from the sequence out of order (adjacent transpositions) or cue an item from a different sequence that is embedded in a similar context (nonadjacent transpositions).

\section{Serial Order and Rapid Execution}

Another strategy for investigating how order information is represented is to examine tasks in which serially ordered sequences are produced at a high rate. Lashley (1951) argued that classic chaining theories could not account for the rapid execution of skilled tasks, like speaking, typing, and playing piano. Classic chaining theories assume that feedback from the current action triggers the next action in the sequence, so execution rates would be limited by the time it takes to receive afferent information that indicates the current action has been executed. However, modern chaining theories assume that feedback from the motor command, rather than the action, serves as the stimulus for the subsequent action (efference copy; Desmurget \& Grafton, 2000). Position coding theories assume that the cueing of sequential position codes triggers each associated action, so execution can proceed as rapidly as each successive position code can be cued. The system does not have to wait for the item associated with the position code to be accessed before cuing the next position code.

\section{Priming Motor Programs}

Theories of skilled typing assume that reaction time (RT) for the first keystroke reflects the time it takes to encode the material to be typed, prepare a motor program to type it, and implement the first step of the program (i.e., execute the first keystroke). Interkeystroke latencies reflect the time it takes to implement each successive step of the program (Crump \& Logan, 2010; Logan \& Crump, 2011; Salthouse, 1986). Motor programs are representations that specify the movements to be executed to achieve a goal and their order of execution (Keele, Cohen, \& Ivry, 1990; Miller, Galanter, $\&$ Pribram, 1960). The assumption that motor programs specify all of the movements before the first movement is executed is supported by at least three lines of evidence: The time it takes to begin an action increases with the complexity of the action, consecutive movements are frequently coarticulated, and initial movements frequently respect end-state rather than beginning-state comfort (Keele, 1968; Rosenbaum, Cohen, Jax, Weiss, \& van der Wel, 2007; Rosenbaum, Engelbrecht, Bushe, \& Loukopoulos, 1993; Rosenbaum, Hindorff, \& Munro, 1987).

Crump and Logan (2010) used a priming task to show that motor programs specify the identity and the order of the keystrokes typists type. They presented a prime word followed by a probe-a single letter or a word-which typists had to type as quickly and 
accurately as possible. RT was faster when probe letters were from the primed word than when they were not, suggesting that the prime word activated all of the constituent letters in parallel.

We adapted Crump and Logan's (2010) priming paradigm to investigate the problem of serial order in skilled typing. Skilled typists were shown a prime word and were then probed to type a target word. We varied the overlap between the identity and the order of letters in the prime and target. We focused primarily on $\mathrm{RT}$, defined as the interval between the onset of the probe and the execution of the first keystroke, because it reflects the time it takes to create a motor program (plus the time for word encoding and executing the first keystroke). Following Crump and Logan, we assumed that the prime would activate the motor program required to type it, and that would affect the time required to create and implement the motor program for the target. The greater the overlap between prime and target, the less time required to program the target, and the shorter the RT.

\section{The Present Study}

We conducted four experiments using the priming paradigm to distinguish between chaining and position coding theories of serial order in skilled typing. First, we asked whether keystroke identities could be primed separately from the position they occupy in a sequence. Experiment 1 compared the RT of probed target words that were preceded by identity, anagram, and unrelated primes. The results indicated that keystroke identities could not be primed separately from their order. Second, we asked whether keystroke identities could be primed in the correct order but out of sequence. Experiment 2 compared priming the first two keystrokes with priming the last two keystrokes. The results indicated that keystroke identities could be primed when they occur in the correct order at the beginning of the sequence, but not when they occur at the end of the sequence. Experiment 3 compared priming the first and last keystrokes with priming the middle two keystrokes. The results indicated that priming the first and last keystrokes produced an RT advantage, but priming the middle two keystrokes did not. The RT advantage observed when the first two keystrokes were primed in Experiment 2 was more pronounced than the RT advantage observed when the first and last keystrokes were primed in Experiment 3. Experiment 4 asked whether priming has a graded influence that depends on the number of keystrokes that are primed in sequence. We compared RT for probed target words that were preceded by primes that shared the first one, two, three, or four keystrokes with the target. The results indicated that priming increased with the number of keystrokes that were primed in sequence and was graded across the keystroke sequence, with less priming in later positions.

\section{Experiment 1}

The purpose of Experiment 1 was to determine whether keystroke identities can be primed separately from their order. Position coding theories of serial order suggest that item and order information are represented separately, so priming a sequence of keystrokes should activate the identities of all the keystrokes separately from their order. Chaining theories suggest that item and order information are represented jointly, so priming a sequence of keystrokes should activate keystroke identities only in the sequence that was primed.
On each trial, typists were presented with a prime word and were told to prepare to type it (see Figure 1). When typists prepare to type a word, the motor system activates the relevant item and order information and maintains this information in a motor program. To ensure that the typists prepared to type the prime, the prime was followed by a go signal (i.e., ${ }^{* * * * *}$ ) that prompted the typists to type the prime in $25 \%$ of the trials. In the remaining trials, the prime was followed by a target that was identical to the prime, an anagram of the prime, or a word that was unrelated to the prime.

When the target is identical to the prime, the motor system only needs to execute the motor program that was prepared for the prime. When the target is unrelated to the prime, the motor program that was prepared for the prime is no longer appropriate, so the motor system needs to generate a new motor program by activating and ordering a new set of keystrokes. As a result, RT should be shorter when targets follow identical primes than when they follow unrelated primes. When the target is an anagram of the prime, the motor program that was prepared for the prime activated all of the keystrokes necessary to type the target, but in an inappropriate order. Thus, the motor program needs to be changed. The cognitive system may do this by creating a new program or revising the existing program. In either case, the residual activation of the shared keystrokes will affect RT differently depending on whether item and order information are represented jointly or separately.

If item and order are represented jointly, as serial chaining theories suggest, the motor system would need to activate a chain of keystrokes that are linked in a specific sequence, just as it would when targets follow unrelated primes. Thus, RT should be as long when targets follow anagram primes as when targets follow unrelated primes. If item and order are represented separately, as position coding theories suggest, the motor system would need to associate the active keystrokes with different position codes. The activation of the keystrokes may decrease the amount of time it takes to create a motor program for the target, so RT may be shorter when targets follow anagram primes than when they follow unrelated primes. However, the activated keystrokes may have to be dissociated from the positions codes they were associated with and reassigned to new position codes. That may increase the time it takes the motor system to create a motor program for the target,

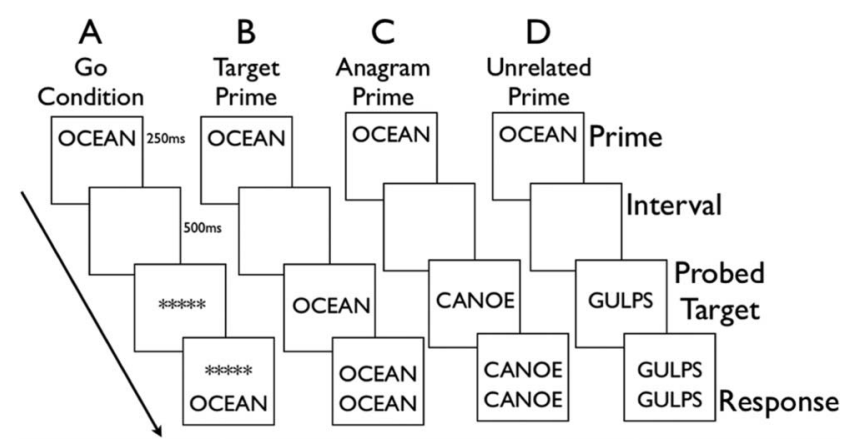

Figure 1. Schedule of events that took place in each trial during Experiment 1. Go trials are depicted in Panel A. Target prime trials are depicted in Panel B. Anagram prime trials are depicted in Panel C. Unrelated prime trials are depicted in Panel D. 
so RT may be longer when targets follow anagram primes than when they follow unrelated primes (Neill \& Mathis, 1998; Neill, Valdes, Terry, \& Gorfein, 1992). In either case, the motor system has to associate the keystrokes with the appropriate position codes, so RT should be longer when targets follow anagram primes than when they follow identical primes.

\section{Method}

Subjects. We recruited 17 typists who had formal training in touch typing and the self-reported ability to type 40 WPM. We did not use the data from one typist who did not follow task instructions. We verified their typing skill with a typing test (for details, see WPM Logan \& Zbrodoff, 1998). Their average typing speed was 72.2 WPM (range $=43.6-121.5 \mathrm{WPM}$ ) and their mean accuracy was $93.4 \%$ (range $=82.9 \%-100 \%$ ). They received course credit or $\$ 12$ for 60 min of participation.

Apparatus and materials. We compiled a pool of 194 fiveletter words from the MRC Psycholinguistic Database (Wilson, 1987). The mean word frequency per million words was 52.0 (range $=.01-1139.2)$, as verified by the Corpus of Contemporary American English (Davies, 2008). Each word was an anagram of another word in the list (see Appendix A). No anagrams shared first letters.

The experiment took place on a personal computer programmed in LIVECODE (http://livecode.com) using a 15-in. SVGA monitor. Typists sat about $57 \mathrm{~cm}$ from the monitor. Responses were registered on a standard QWERTY keyboard. The program blackened the screen and displayed a $24.1 \mathrm{~cm} \times 19.7 \mathrm{~cm}$ gray window. The prime word was displayed $5.1 \mathrm{~cm}$ from the top of the window in black 40-point Helvetica font. The probe was presented $6.4 \mathrm{~cm}$ from the top of the window in the same font. Typists' responses were echoed $3.8 \mathrm{~cm}$ below the probe.

Procedure. At the beginning of each trial, a prime word was displayed for $250 \mathrm{~ms}$. It was subsequently removed. After a $500-\mathrm{ms}$ blank interval, the probe was displayed. The probe was either a go stimulus (i.e., ${ }^{* * * * *}$ ) or a target word. There were four conditions (see Figure 1). In the go condition, typists were primed with a word and probed with the go stimulus (Figure 1, Panel A). In the target prime condition, typists were primed with the target word and probed with the target word (Figure 1, Panel B). In the anagram prime condition, typists were primed with an anagram of

\section{Reaction Time}

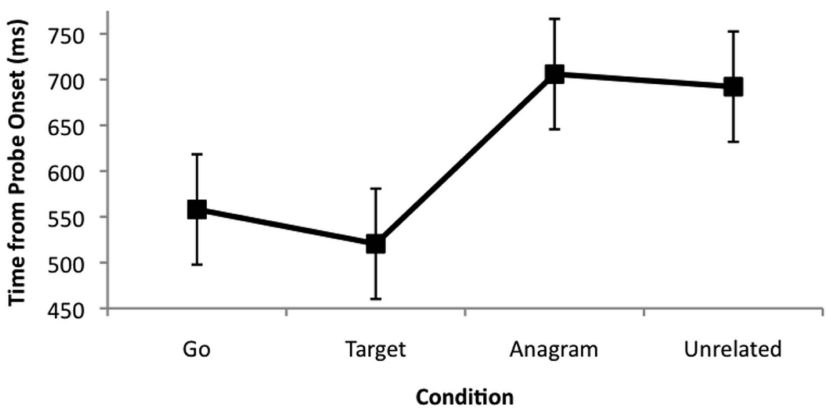

Figure 2. Average reaction time for each condition in Experiment 1. Error bars display Fisher's least significant difference for $p<.05$.
Table 1

Summary Tables for One-Way Analyses of Variance (ANOVA) Conducted on Response Times (RTs) and Error Rate (ER) Data From Experiment 1

\begin{tabular}{crcc}
\hline Measure & MSE & $F$ & $\eta_{p}^{2}$ \\
\hline RT & 7178.5 & $19.6^{*}$ & .566 \\
ER & 4.9 & $<1$ & .057 \\
\hline
\end{tabular}

Note. Degrees of freedom for each effect $=3,45 . F=\mathrm{F}$ statistic; $M S E=$ mean standard error.

${ }^{*} p<.05$.

the target word and probed with the target word (Figure 1, Panel C). In the unrelated prime condition, typists were primed with a randomly selected word that was not the target word or an anagram of the target word, and then probed with a target word (Figure 1, Panel D). Each of the 194 words served as a prime four times, once per condition, resulting in a total of 776 trials.

Typists were instructed to pay attention to the prime word and to prepare to type it as soon as the go stimulus appeared. If a word was displayed instead of the go stimulus, typists were to type that word as quickly and accurately as possible. The backspace key was disabled, so typists were not able to correct their responses. Typists pressed the spacebar to move on to the next trial. Once typists finished the experiment, they completed the typing test.

\section{Results and Discussion}

We calculated mean RT from correct trials. We excluded RTs that were more than 2.5 standard deviations from the mean (Van Selst \& Jolicoeur, 1994). This excluded $2.6 \%$ of the data. We also calculated mean error rates (i.e., percentage of trials in which at least one typing error was committed) for each condition for each typist. Mean RTs across typists are presented in Figure 2. We conducted one-way analyses of variance (ANOVAs) on the RT and error rates. The summary tables for the ANOVAs are presented in Table 1.

ANOVA revealed that RT differed significantly between the conditions. To determine which differences were significant, we calculated Fisher's least significant difference (LSD), which was $60 \mathrm{~ms}$ for $p<.05$. We also calculated the Bonferroni-corrected minimum mean difference, which was $83 \mathrm{~ms}$ for the adjusted alpha level of .008 per test (.05/6). Using either criterion, RT did not differ significantly between go $(M=558 \mathrm{~ms})$ and target prime trials $(M=521 \mathrm{~ms})$, which suggests that typists were prepared to type the prime. RT in unrelated prime trials $(M=692 \mathrm{~ms})$ was significantly longer than both go and target prime trials. RT in anagram prime trials $(M=706 \mathrm{~ms})$ was significantly longer than in target prime trials. RT did not differ significantly between anagram and unrelated trials $(M=692 \mathrm{~ms})$. These findings indicate that it takes the motor system approximately the same amount of time to reorder a set of previously activated keystrokes as it does to activate and order a new set of keystrokes. These results are consistent with the notion that item and order information are represented jointly, not separately, in skilled typewriting. There were no significant differences in error rates between the conditions (go: $M=10.1 \%$; target: $M=9.2 \%$; anagram: $M=10.3 \%$; unrelated: $M=10.3 \%$ ). 


\section{Experiment 2}

The results of Experiment 1 indicated that key identities were not primed separately from their order. The findings were more consistent with chaining theories than position coding theories, but they do not rule out position coding theories entirely. Although keystroke identities were the same in target and anagram primes, the keystrokes that were associated with position codes differed. If typists represent serial order by position coding, priming may be produced only when keystroke identities are associated with the same position code in the prime and the target.

In Experiment 2, we tested whether a prime would facilitate RT if two of the keystroke identities in the prime and target were associated with the same position codes, but occurred in different sequences. We compared primes in which keystroke identities were the same as the target in the first two positions but differed in the last two positions (SSDD trials), primes in which keystroke identities were the same as the target in the last two positions but differed in the first two positions (DDSS trials), primes in which keystroke identities were the same as the target in all four positions (SSSS trials), and primes in which the keystroke identities differed from the target in all four positions (DDDD trials), in which S and $\mathrm{D}$ indicate whether the keystroke identity associated with a position was the same $(\mathrm{S})$ or different $(\mathrm{D})$ in the prime and target.

If serial order is represented by position coding, RT should be faster for targets that follow both SSDD and DDSS primes than for targets that follow DDDD primes. When targets follow SSDD and DDSS primes, the associations between two keystrokes and two positions are the same in the prime and the target. The activation in these positions should reduce the amount of time needed to prepare a motor program for the target. If serial order is represented by chaining, RT should be faster for targets that follow SSDD primes than for targets that follow DDDD primes, but RT should not be faster targets that follow DDSS primes than for targets that follow DDDD primes. Chaining theories assume that motor programs are prepared from the beginning of the sequence. In SSDD trials, the first two links in the chain are primed, which should reduce the amount of time needed to prepare them. In DDSS trials, the last two keystrokes are primed, but they follow two unprimed keystrokes. A new chain would need to be established from the beginning of the sequence, so the advantage of priming would be lost.

It is possible that the priming effects on RT reflect visual priming that reduces the time it takes to encode the target. We did not think that visual priming was likely because Peressotti and Grainger (1999) found no priming from visual primes that partially overlapped with targets in a recognition task, and Crump and Logan (2010) found equivalent priming with visual and auditory primes in a typing task. Nevertheless, we thought it was important to determine whether the priming effects are visual or motor, so we ran two groups of typists. One group received a visual prime, as in Experiment 1 and the experiments that follow. The other group received an auditory prime. If the priming is visual and perceptual, rather than motor, there should be no priming in the auditory group. If priming is motor, there should be priming in both the visual and auditory groups.

Priming effects in RT reflect the time it takes to prepare a motor program and implement the first step in program. To determine whether priming affects the implementation of subsequent steps in the program, we analyzed interkeystroke latencies. The second keystroke latency (L2) corresponds to the interval between the first and second keystroke. The third keystroke latency (L3) corresponds to the interval between the second and third keystroke. The fourth keystroke latency (L4) corresponds to the interval between the third and fourth keystroke. We focused our analyses on L3, which reflects the latency before the first unprimed keystroke in SSDD trials and before the first primed keystroke in DDSS trials.

Both serial chaining and position coding predict that L3 would be longer in SSDD trials than in DDDD trials. The first two keystrokes are primed in SSDD trials but not in DDDD trials, so the second keystroke should be executed faster in SSDD than in DDDD trials. Serial chaining predicts that L3 should not differ between DDSS and DDDD primes because the motor system would need to prepare a new chain of four keystrokes in both conditions. Position coding predicts that L3 will be shorter in DDSS than in DDDD trials because the last two keystrokes are primed in DDSS trials but not in DDDD trials.

\section{Method}

Subjects. Two new groups of 16 skilled typists were recruited from the same population as Experiment 1. For the visual prime group, average typing speed was 77.8 WPM (range $=46.5-119.3$ WPM). Average typing accuracy was $93.8 \%$ (range $=86.4 \%$ $97.3 \%$ ). For the auditory prime group, average typing speed was 83.9 WPM (range $=50.0-113.5 \mathrm{WPM})$. Average typing accuracy was $93.2 \%$ (range $=84.8 \%-98.2 \%)$.

Apparatus, stimuli, and procedure. The priming procedure was the same for both groups, except for the presentation of the prime. We compiled a pool of 100 four-letter words from the MRC Psycholinguistic Database (Wilson, 1987). The mean word frequency per million words was 108.3 (range $=.41-4788.3$ ), as verified by the Corpus of Contemporary American English (Davies, 2008). Word selection was based on the following criteria: the word consisted of four different letters, the word shared no letters with at least one other word in the list, the word shared only the first two letters with another word in the list, and the word shared only the last two letters with another word in the list (see Appendix B).

There were five conditions. The go condition occurred on $20 \%$ of the trials. In go trials, the target word was presented as the prime. A series of four asterisks was presented as the probe. In SSSS, SSDD, DDSS, and DDDD trials, a word was presented as the probe. In SSSS trials, the probe was the same as the prime (e.g., busy $=>$ busy). In SSDD trials, the first two letters of the prime were the same as the target, and the last two letters of the prime were different from the target (e.g., busy $=>$ burn). In DDSS trials, the first two letters of the prime differed from the target, and the last two letters of the prime were the last two letters of the target (e.g., busy = > easy). In DDDD trials, all four of the prime's letters differed from the target (e.g., busy $=>$ wait). Each of the 100 words served as a prime in each of the five conditions, which resulted in a total of 500 trials. All other apparatuses and procedures were the same as Experiment 1.

For the auditory prime group, synthesized versions of the prime words were generated using the Apple Macintosh voice synthesizer (Apple Corp., Cupertino, CA). The average duration of the synthesized primes was $530 \mathrm{~ms}$ (range $=416-643 \mathrm{~ms}$; standard 
deviation $=45 \mathrm{~ms}$ ). Auditory primes were played through headphones. The probe was presented visually $750 \mathrm{~ms}$ after the onset of the auditory prime to match the stimulus onset asynchrony between the visual prime and the target. All other aspects of the procedure were the same as in the visual prime group.

\section{Results and Discussion}

Visual prime group. We calculated error rate and mean RT for correct trials for each condition for each typist. We removed RTs that were more than 2.5 standard deviations from the mean (Van Selst \& Jolicoeur, 1994), which excluded $2.7 \%$ of the data. Mean RTs across typists are displayed in Figure 3 (solid line). We conducted one-way ANOVAs on the RTs and error rates. The summary tables for the ANOVAs are presented in Table 2.

There were significant differences in RT between the conditions. Fisher's LSD for $p<.05$ was $29 \mathrm{~ms}$. Bonferroni-corrected minimum mean difference was $42 \mathrm{~ms}$ for the adjusted alpha level of .005 (.05/10). Using either criterion, RT was significantly shorter in go trials $(M=583 \mathrm{~ms})$ than in DDDD trials $(M=659)$, indicating that typists were prepared to type the prime. RT was significantly shorter in $\operatorname{SSSS}(M=512 \mathrm{~ms})$ than SSDD trials $(M=581 \mathrm{~ms})$, and significantly shorter in SSDD than in DDSS $(M=660 \mathrm{~ms})$. RT did not differ significantly between DDSS and DDDD trials $(M=659 \mathrm{~ms})$. These findings indicate that priming the keystrokes in the first two, but not the last two, positions reduces the amount of time it takes to prepare the motor program for the target word and execute the first keystroke. This suggests that skilled typists represent order with serial chaining and not position coding. There were no significant differences in error rate between the conditions (Go: $M=8.6 \%$; SSSS: $M=8.3 \%$; SSDD: $M=7.3 \%$; DDSS: $M=6.8 \%$; DDDD: $M=7.1 \%$ ).

Interkeystroke latencies were calculated from correct trials for each condition for each typist. One-way ANOVAs conducted on the mean L2, L3, and L4 measures indicated significant differences between conditions for all three intervals (see Table 2). We focused on L3 because it was the interval before the first unprimed keystroke in SSDD trials and before the first primed keystroke in DDSS trials. Average L3 for each condition are displayed with a solid line in Figure 4. L3 was calculated by subtracting the RT of

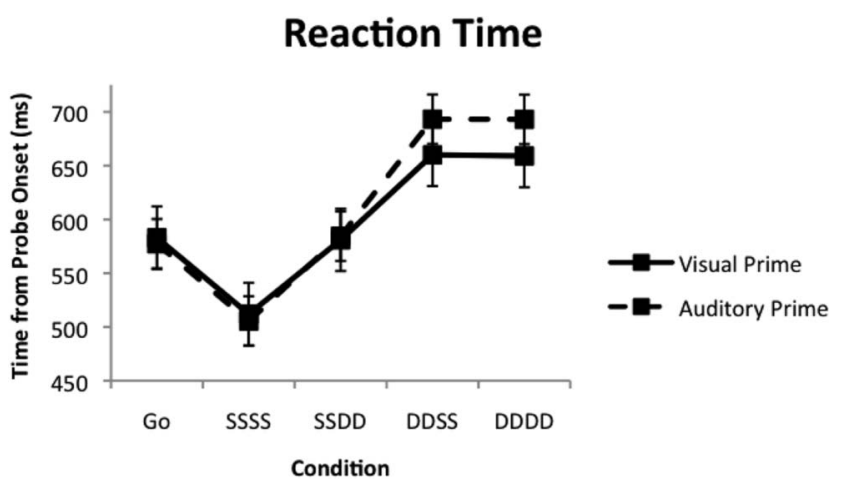

Figure 3. Average reaction time (RT) for each condition in Experiment 2. Visual prime RTs are represented with the solid line. Auditory prime RTs are represented with the dashed line. Error bars display Fisher's least significant difference for $p<.05$.
Table 2

Summary Table for One-Way ANOVAs Conducted on Response

Time (RT), Latencies Between Successive Keystrokes (L2, L3, and L4), and Error Rate (ER) Data From Experiment 2

\begin{tabular}{crrrrrrrr}
\hline & \multicolumn{3}{c}{ Visual prime } & & \multicolumn{3}{c}{ Auditory prime } \\
\cline { 2 - 3 } \cline { 7 - 8 } Measure & MSE & \multicolumn{1}{c}{$F$} & $\eta_{p}^{2}$ & & MSE & $F$ & $\eta_{p}^{2}$ \\
\hline RT & 1667.6 & $37.4^{*}$ & .713 & & 1062.2 & $99.6^{*}$ & .869 \\
L2 & 43.6 & $4.3^{*}$ & .223 & & 72.9 & $9.0^{*}$ & .374 \\
L3 & 43.3 & $12.4^{*}$ & .452 & & 101.2 & $13.4^{*}$ & .471 \\
L4 & 55.2 & $4.9^{*}$ & .245 & & 64.8 & 2.4 & .139 \\
ER & 5.9 & 1.6 & .099 & & 19.1 & $8.6^{*}$ & .364 \\
\hline
\end{tabular}

Note. Degrees of freedom for each effect $=4,60 . F=\mathrm{F}$ statistic; $M S E=$ mean standard error.

$* p<.05$.

the third keystroke (RT3) from the RT of the second keystroke (RT2). Outlier analyses excluded $2.6 \%$ of the data. Fisher's LSD for $p<.05$ was $5 \mathrm{~ms}$. Bonferroni-corrected minimum mean difference was $7 \mathrm{~ms}$ for the adjusted alpha level of .005 (.05/10). Using either criterion, L3 was significantly longer in SSDD $(M=$ $132 \mathrm{~ms}$ ) than in DDDD trials $(M=122 \mathrm{~ms})$. L3 did not differ significantly between DDDD and DDSS $(M=120 \mathrm{~ms})$ trials. These results are consistent with serial chaining.

Auditory prime group. Mean RTs, L3, and error rates were calculated as before. Outlier analyses excluded $2.6 \%$ of the RT data and $2.6 \%$ of the L3 data. Mean RTs across typists are displayed in Figure 3 (dashed line). The summary tables for the ANOVAs conducted on RTs, L3, and error rates are presented in Table 2 .

Auditory primes produced the same differences in RT between conditions as visual primes. Fisher's LSD for $p<.05$ was $23 \mathrm{~ms}$. Bonferroni-corrected minimum mean difference for was $34 \mathrm{~ms}$ for the adjusted alpha level of $.005(.05 / 10)$. Using either criterion, RT was significantly shorter in go trials $(M=577 \mathrm{~ms})$ than in DDDD trials $(M=693)$. RT was significantly shorter in SSSS $(M=506$ $\mathrm{ms})$ than SSDD trials $(M=585 \mathrm{~ms})$, and significantly shorter in SSDD than in DDSS ( $M=693 \mathrm{~ms})$. RT did not differ significantly between DDSS and DDDD trials. These findings indicate that

\section{Latency 3}

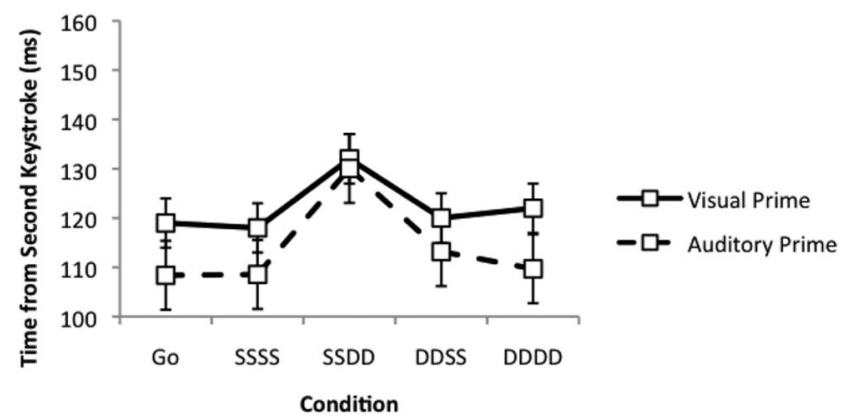

Figure 4. Average interkeystroke latency between the second and third keystroke (L3) for Experiment 2. Visual prime reaction times (RTs) are represented with the solid line. Auditory prime RTs are represented with the dashed line. Error bars display Fisher's least significant difference for $p<.05$. 
auditory and visual primes affected RT in the same way, which suggest that the locus of the priming effect is motor rather than visual.

There were significant differences in error rate between auditory prime conditions. Fisher's LSD was 3.1\%. Bonferroni-corrected minimum mean difference for was $4.5 \%$. Using either criterion, error rates in go trials $(M=17.4 \%)$ were higher than error rates in SSSS trials $(M=9.2 \%)$, SSDD trials $(M=10.1 \%)$, DDSS trials $(M=12.5 \%)$, and DDDD trials $(M=12.3 \%)$. Using the Fisher's LSD criterion, errors rates were marginally higher in DDSS and DDDD trials than in SSSS trials.

Average L3 across conditions are displayed in Figure 4 (dashed line). Fisher's LSD was $7 \mathrm{~ms}$. Bonferroni-corrected minimum mean difference for was $11 \mathrm{~ms}$. Again, the L3 results for the auditory prime group mirrored the L3 results for the visual prime group. Using either criterion, L3 was significantly longer in SSDD $(M=130 \mathrm{~ms})$ than in DDDD trials $(M=110 \mathrm{~ms})$. L3 did not differ significantly between DDDD and DDSS $(M=113 \mathrm{~ms})$ trials.

The effects of visual versus auditory primes. To assess the effects of visual versus auditory primes, we conducted ANOVAs on RT, L3, and error rate, with prime group as a between-subjects factor. The interaction was not significant for RT, $F(4,120)<1$, $M S E=1364.9, p=.06$, or L3, $F(4,120)=1.8, M S E=72.3, p=$ .14 , but it was significant for error rate, $F(4.120)=5.9, M S E=$ $12.5, p<.001$. Typists in the auditory prime group may have had difficulty discerning some of the synthesized words, which could have led to higher error rates, especially in go trials.

\section{Experiment 3}

In Experiment 3, we continued to test whether priming some of the keystrokes would facilitate the preparation and implementation of the sequence. In Experiment 2, the first (SSDD) or second (DDSS) half of a keystroke sequence was primed. In Experiment 3 , the beginning and end (SDDS) or the middle (DSSD) of a keystroke sequence was primed. The auditory primes in Experiment 2 established that priming was motor and not visual, so we used visual primes in Experiment 3 and subsequent experiments. Targets could also follow primes that shared all four keystrokes (SSSS) or none of the keystrokes (DDDD). If keystroke order is represented by position coding, RT should not differ between SDDS and DSSD trials, and RT in SDDS and DSSD trials should be shorter than RT in DDDD trials. If keystroke order is represented by serial chaining, RT should be shorter in SDDS than in DSSD and DDDD trials, and RT should not differ between DSSD and DDDD trials.

In addition to RT, we analyzed L2 and L4 keystroke latencies to compare primed and unprimed keystrokes. If keystroke order is represented by position coding, L2 should be shorter in DSSD than in DDDD trials, and L4 should be shorter in SDDS than in DDDD trials. If keystroke order is represented by serial chaining, L2 should not differ between DSSD, and DDDD trials and L4 should not differ between SDDS and DDDD trials.

\section{Method}

Subjects. A new group of 16 skilled typists was recruited from the same population as the previous experiments. Their average typing speed was 77.3 WPM (range $=52.8-95.5 \mathrm{WPM})$. Their average accuracy was $94.0 \%$ (range $=87.9 \%-100 \%$ ).

Apparatus, stimuli, and procedure. We compiled a new pool of 100 four-letter words from the MRC Psycholinguistic Database (Wilson, 1987). The mean word frequency per million words was 61.1 (range $=.01-970.2$ ), as verified by the Corpus of Contemporary American English (Davies, 2008). Word selection was based on the following criteria: the word consisted of four different letters, the word shared no letters with at least one other word in the list, the word shared only the first and fourth letters with another word in the list, and the word shared only the second and third letters with another word in the list (see Appendix C).

There were five conditions, and each occurred on $20 \%$ of the trials: go, SSSS, SDDS, DSSD, and DDDD. The go, SSSS, and DDDD conditions were the same as in Experiment 2. In the SDDS condition, the first and fourth letters of the prime matched the target, and the second and third letters were different (e.g., fire $=>$ fuse). In the DSSD condition, the first and fourth letters of the prime differed from the target, and the second and third letters of the prime matched the target (e.g., fire $=>$ girl). Each of the 100 words served as a prime in each of the five conditions, which resulted in a total of 500 trials. All other apparatuses and procedures were the same as in Experiment 2.

\section{Results and Discussion}

Error rates and mean RT for correct trials were calculated for each condition for each subject. Mean RTs across typists are displayed in Figure 5. Figure 6 displays mean L2 (A) and L4 (B), averaged across typists. We conducted one-way ANOVAs on the RT, L2, L3, L4, and error rate data. The summary tables for the ANOVAs are presented in Table 3.

Outlier analyses excluded $2.8 \%$ of the RT data. RTs differed significantly between conditions. Fisher's LSD for $p<.05$ was 29 $\mathrm{ms}$. Bonferroni-corrected minimum mean difference was $43 \mathrm{~ms}$ for the adjusted alpha level of .005 (.05/10). Using either criterion, RT was significantly shorter in SSSS trials $(M=508 \mathrm{~ms})$ than in SDDS trials $(M=630 \mathrm{~ms})$ trials, and significantly shorter in SDDS trials than in DSSD trials $(M=694 \mathrm{~ms})$. RT did not differ significantly between DSSD and DDDD $(M=678 \mathrm{~ms})$ trials. These findings are consistent with serial chaining.

L2 was calculated by subtracting the RT of the second keystroke (RT2) from the RT of the first keystroke (RT). Outlier analyses

\section{Reaction Time}

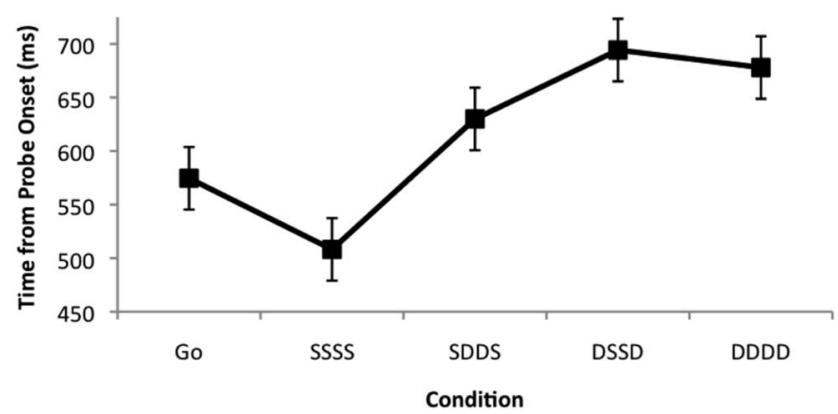

Figure 5. Average reaction time for each condition in Experiment 3. Error bars display Fisher's least significant difference for $p<.05$. 
excluded $2.8 \%$ of the RT2 data. The ANOVA conducted on the L2 data indicated that L2 differed marginally between conditions. Fisher's LSD for $p<.05$ was $4 \mathrm{~ms}$. Bonferroni-corrected minimum mean difference for the adjusted alpha level of .005 (.05/10) was $6 \mathrm{~ms}$. Using either criterion, L2 was significantly longer in SDDS $(M=143 \mathrm{~ms})$ trails than in SSSS $(M=120 \mathrm{~ms})$, DSSD ( $M=128 \mathrm{~ms})$, or DDDD ( $M=124 \mathrm{~ms})$ trials. This result is consistent with both serial chaining and position coding theories. The Fisher LSD criterion suggests that L2 was marginally longer in DSSD than in DDDD trials. This result is inconsistent with both theories: Chaining theories would predict that L2 should not differ between DSSD and DDDD trials. Position coding theories would predict that L2 should be shorter in DSSD than in DDDD trials.

L3 was calculated by subtracting the RT of the fourth keystroke (RT4) from the RT of the third keystroke (RT3). Outlier analyses excluded $2.8 \%$ of the RT3 data and $2.6 \%$ of the RT4 data. The ANOVA conducted on the L4 data indicated no significant differences between the conditions. Fisher's LSD for $p<.05$ was 5 ms. Bonferroni-corrected minimum mean difference was $7 \mathrm{~ms}$ for adjusted $p<.005$. Using this criterion, L4 did not differ significantly between SSSS ( $M=128 \mathrm{~ms}), \operatorname{SDDS}(M=129 \mathrm{~ms})$, DSSD $(M=125 \mathrm{~ms})$, and DDDD $(M=127 \mathrm{~ms})$ trials. Position coding predicts that priming keystrokes that occur in common positions facilitates keystroke execution, so these null results are more consistent with serial chaining than with position coding. There were also no significant differences in error rates between the conditions (go: $M=8.3 \%$; SSSS: $M=8.5 \%$; SDDS: $M=8.1 \%$; DSSD: $M=10.3 \%$; DDDD: $M=7.3 \%$ ).

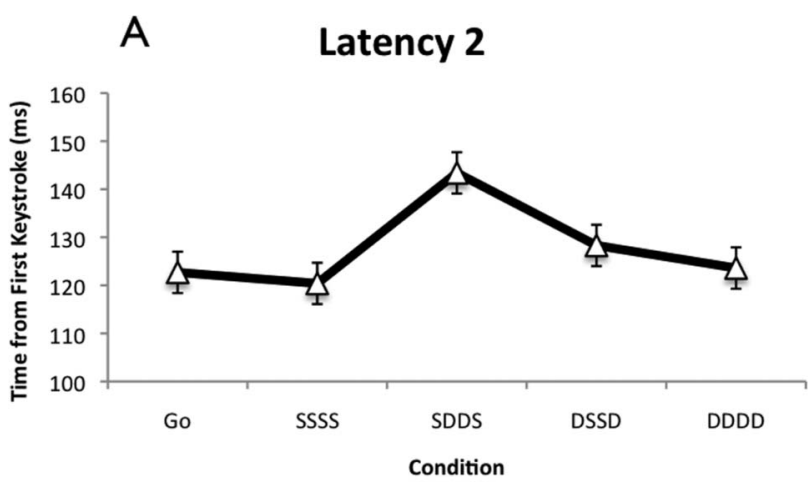

B Latency 4

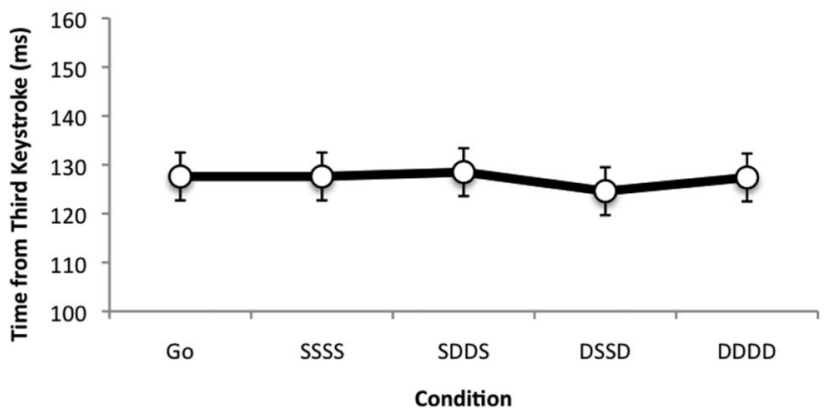

Figure 6. Average interkeystroke latencies for Experiment 3. Panel A depicts the average latency between the first and second keystroke (L2). Panel B depicts the average latency between the third and fourth keystroke (L4). Error bars display Fisher's least significant difference for $p<.05$.
Table 3

Summary Tables for One-Way ANOVAs Conducted on Response Time (RT), Latencies Between Successive Keystrokes (L2, L3, and L4), and Error Rate (ER) Data From Experiment 3

\begin{tabular}{crcc}
\hline Measure & $M S E$ & $F$ & $\eta_{p}^{2}$ \\
\hline RT & 1704.3 & $55.2^{*}$ & .786 \\
L2 & 37.2 & 4.0 & .211 \\
L3 & 65.9 & 1.3 & .082 \\
L4 & 47.8 & $<1$ & .047 \\
ER & 9.3 & 2.0 & .119 \\
\hline
\end{tabular}

Note. Degrees of freedom for each effect $=4,60 . F=\mathrm{F}$ statistic; $M S E=$ mean standard error.

$* p<.05$.

\section{Experiment 4}

The RT results of Experiments 2 and 3 were consistent with chaining theories of serial order. The L3 results of Experiment 2 and the L2 results of Experiment 3 were also consistent with serial chaining. However, the L4 analyses of Experiment 3 were not entirely consistent with serial chaining or position coding.

These conclusions are based on the assumption that priming influences each item in a sequence equally. However, this may not be the case. Priming may influence items in a sequence differentially. The results of Experiments 2 and 3 suggest that priming may depend on at least two factors. First, priming may be stronger when more keystrokes are primed consecutively. The RT difference between SSDD and DDDD trials in the visual prime group of Experiment 2 (78 $\mathrm{ms}$ ) was $30 \mathrm{~ms}$ larger than the RT difference between SDDS and DDDD trials in Experiment 3 (48 ms). Second, priming may be stronger for earlier positions in sequence than for later positions. The L2 difference between SDDS and DDDD trials in Experiment 3 (21 ms) was $11 \mathrm{~ms}$ larger than the L3 difference between SSDD and DDDD trials in the visual prime group of Experiment $2(10 \mathrm{~ms})$. L4 differences in Experiment 3 were not larger than $4 \mathrm{~ms}$. The purpose of Experiment 4 was to test, within subjects, whether keystrokes are primed equally across serial positions.

In Experiment 4, we varied the number of keystrokes that were primed in sequence. Typists were primed with words that shared all keystrokes (SSSS), the first three keystrokes (SSSD), the first two keystrokes (SSDD), the first keystroke (SDDD), or no keystrokes (DDDD) with the target word. If priming depends on the number of keystrokes that are primed in sequence, RT should be shorter when more keystrokes are primed than when fewer keystrokes are primed. If priming depends only on priming the first keystroke, RT should not differ between SSSS, SSSD, SSDD, and SDDD trials. If priming affects keystrokes more at the beginning of a sequence than at the end of a sequence, the L2 difference between SDDD and DDDD trials should be larger than the L3 difference between SSDD and DDDD trials, and the L3 difference should be larger than the L4 difference between SSSD and DDDD trials.

\section{Method}

Subjects. A new group of 17 typists was recruited from the same population as before. We excluded data from one typist who 
did not follow task instructions. Average typing speed was 66.3 WPM (range $=47.2-107.9 \mathrm{WPM})$. Average typing accuracy was $92.6 \%$ (range $=87.2 \%-99.1 \%$ ).

Apparatus, stimuli, and procedure. We compiled a pool of 104 four-letter words from the MRC Psycholinguistic Database (Wilson, 1987). The mean word frequency per million words was 158.2 (range $=.29-4864.9$ ), as verified by the Corpus of Contemporary American English (Davies, 2008). Word selection was based on the following criteria: the word consisted of four different letters, the word shared no letters with at least one other word in the list, the word shared only the first letter with another word, the word shared only the first and second letters with another word, and the word shared the first, second, and third letters with another word (see Appendix D).

There were six conditions, and each occurred on one sixth of the trials: go, SSSS, SSSD, SSDD, SDDD, and DDDD. The go, SSSS, DDDD, and SSDD trials were the same as in Experiment 2. In SSSD trials, the first, second, and third letters of the prime were the same as the target, and the last letter was different (e.g., hair $=>$ hail). SDDD trials, the first letter of the prime was the same as the target, and the second, third, and fourth letter were different (e.g., hair $=>$ hunk). Each of the 104 words served as a prime in each of the six conditions, which resulted in a total of 624 trials. All other apparatuses and procedures were the same as the previous experiments.

\section{Results and Discussion}

Figure 7 displays mean RT averaged across typists for each condition. Figure 8 displays mean L2 (A), L3 (B), and L4 (C) averaged across typists. We conducted one-way ANOVAs on the RT, error rate, L2, L3, and L4 data (see Table 4). Only RT and interkeystroke latency data from correct trials were analyzed.

We excluded RTs that were more than 2.5 standard deviations from the mean $(3.0 \%$ of the data). RTs differed significantly between the conditions, decreasing monotonically with the number of primed keystrokes. We assessed the significance of the monotonic decrease with a linear trend test, which was highly significant, $F(1,75)=145.42, p<.001$. Error rates differed marginally across conditions (go: $M=6.3 \%$; SSSS: $M=8.6 \%$; SSSD: $M=$ $7.9 \%$; SSDD: $M=7.1 \%$; SDDD: $M=6.9 \%$; DDDD: $M=9.1 \%$ ).

L2 was calculated by subtracting the RT of the second keystroke (RT2) from the first keystroke (RT). L3 was calculated by sub-

\section{Reaction Time}

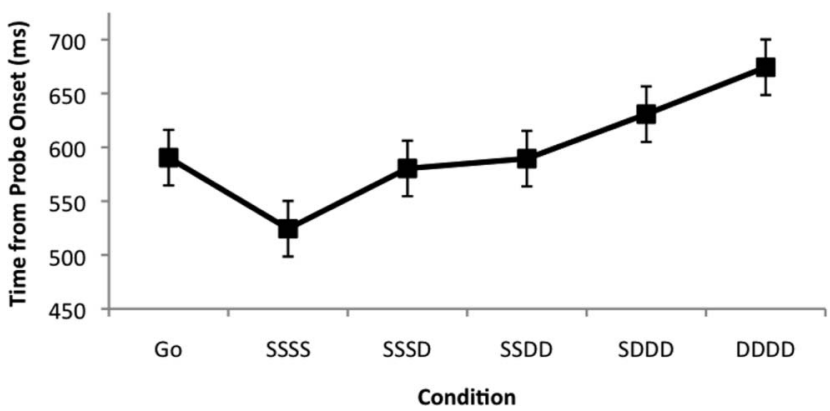

Figure 7. Average reaction time for each condition in Experiment 4. Error bars display Fisher's least significant difference for $p<.05$.

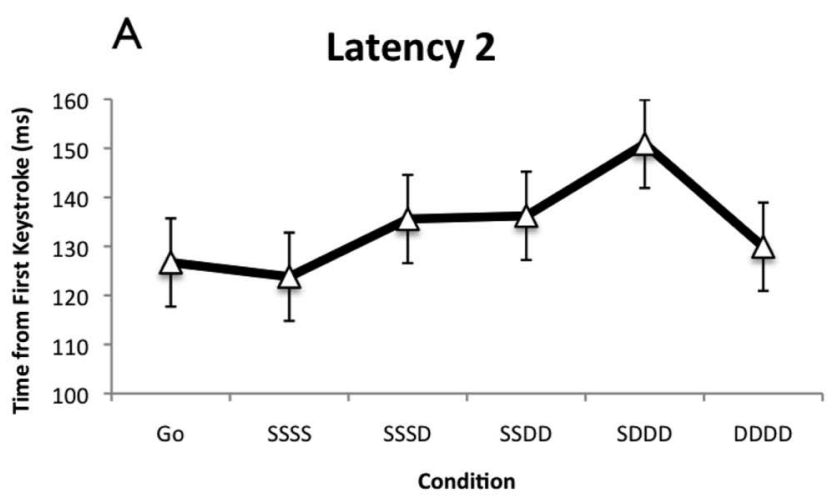

B

Latency 3

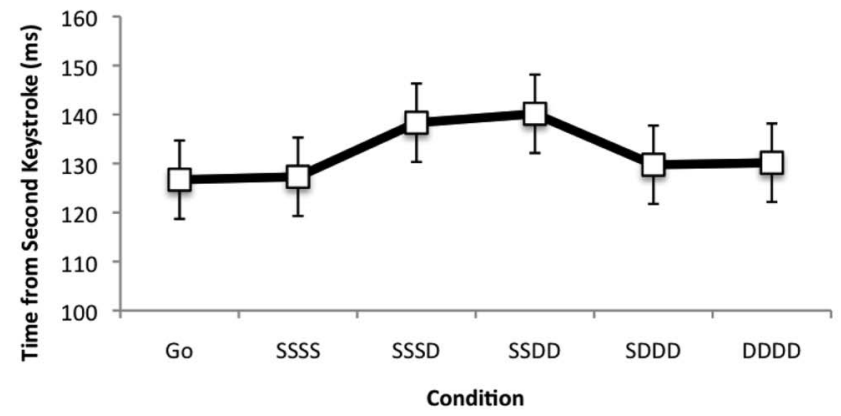

C Latency 4

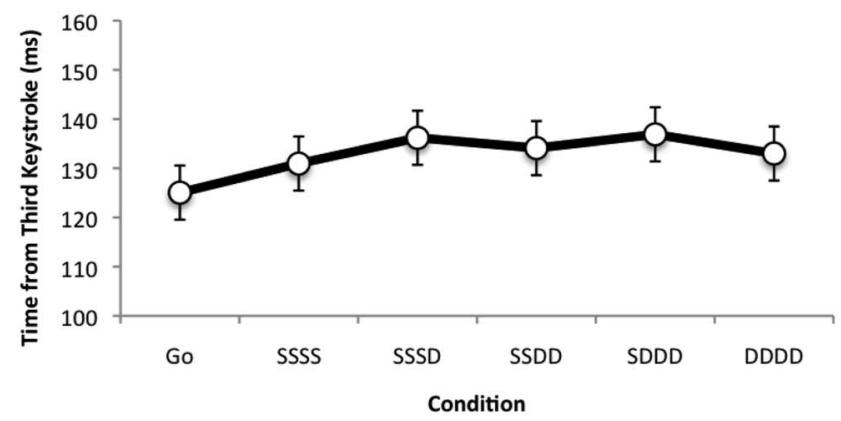

Figure 8. Average interkeystroke latencies for Experiment 4. Panel A depicts the average L2. Panel B depicts the average L3. Panel C depicts the average L4. Error bars display Fisher's least significant difference for $p<$ .05 .

tracting the RT of the third keystroke (RT3) from RT2. L4 was calculated by subtracting the RT of the fourth keystroke (RT4) from RT3. Outlier analyses excluded $2.9 \%$ of the RT2 data, $2.8 \%$ of the RT3 data, and $2.9 \%$ of the RT4 data. Latencies for the first unprimed keystroke, or S-D transition, decreased monotonically across positions. L2 in SDDD trials was $151 \mathrm{~ms}$, L3 in SSDD trials was $140 \mathrm{~ms}$, and L4 in SSSD trials was $136 \mathrm{~ms}$. We assessed the significance of this monotonic decrease with a linear trend test, using a one-way ANOVA on the relevant S-D transitions (i.e., SDDD L2, SSDD L3, and SSSD L4) data. The contrast was significant, $F(1,30)=5.2, M S E=346.1, p<.05$.

Figure 9 displays the interkeystroke latencies for SSSS, DDDD, and the relevant S-D transitions. A 3 (condition: SSSS vs. DDDD 
Table 4

Summary Table for One-Way ANOVAs Conducted on Response

Time (RT), Latencies Between Successive Keystrokes (L2, L3, and L4), and Error Rate (ER) Data From Experiment 4

\begin{tabular}{crrr}
\hline Measure & MSE & $F$ & $\eta_{p}^{2}$ \\
\hline RT & 1340.1 & $30.1^{*}$ & .786 \\
L2 & 175.2 & $8.5^{*}$ & .211 \\
L3 & 130.6 & $4.0^{*}$ & .082 \\
L4 & 61.2 & $4.9^{*}$ & .047 \\
ER & 7.9 & $2.3^{*}$ & .119 \\
\hline
\end{tabular}

Note. $\quad$ Degrees of freedom for each effect $=5,75 . F=\mathrm{F}$ statistic; $M S E=$ mean standard error.

$* p<.05$.

vs. S-D transition) $\times 3$ (transition: L2 vs. L3 vs. L4) ANOVA revealed a significant effect of condition, $F(2,30)=10.0, M S E=$ $295.5, p<.001$, and nonsignificant effect of latency, $F(2,30)<1$, $M S E=369.6, p=.834$. However, the interaction was significant, $F(4,60)=5.5, M S E=101.5, p<.001$. Fisher's LSD for $p<.05$ was $7 \mathrm{~ms}$. Bonferroni-corrected minimum mean difference was 9 $\mathrm{ms}$ for adjusted $p<.008$. We tested the difference in the linear trends of the S-D transitions and the corresponding latencies in DDDD trials. The contrast was significant, $F=186.4, p<.001$. This result indicates a graded reduction in the effect of priming across serial positions. We also tested the difference in the linear trends of the S-D transitions and the corresponding latencies in SSSS trials. The contrast was significant, $F=180.8, p<.001$. This result indicates a graded reduction in the amount of time needed to implement an unprimed keystroke across serial positions. Thus, whether priming is defined as decreased RT for primed versus unprimed responses, or as increased RT for unprimed versus primed responses, our findings indicate that there is a graded reduction in the effect over serial positions.

\section{General Discussion}

We investigated the problem of serial order in skilled typing by asking how typists represent the identity and order of the keystrokes they type. We conducted four experiments that were designed to test whether keystroke identity and order are represented jointly, as chaining theories suggest, or separately, as position coding theories suggest. All four experiments showed that keystrokes primed in the correct order and sequence produced an RT advantage. Experiment 1 showed that keystrokes primed out of order do not produce an RT advantage. Experiments 2 and 3 showed that keystrokes primed in the correct order, but out of sequence, did not produce an RT advantage. Experiment 4 showed that priming is graded across the keystroke sequence and that the $\mathrm{RT}$ advantage is modulated by the number of keystrokes that are primed in sequence.

\section{Serial Order by Chaining}

Chaining theories provide a good account of our findings. Chaining theories assume that keystroke identity and order are represented jointly. Preparing a sequence of keystrokes requires linking a specific sequence of keystrokes into a chain, so there should be no benefit of priming the appropriate keystrokes in an inappropriate order. Accordingly, RTs did not differ between anagram prime and unrelated prime trials in Experiment 1. In addition, there should be no benefit of priming keystrokes in the correct order but out of sequence. Accordingly, RTs did not differ between DDSS and DDDD prime trials in Experiment 2, or between DSSD and DDDD prime trials in Experiment 3. It takes time to add different links to a chain, so RT should be shorter when fewer links need to be added to the chain. Accordingly, RTs were shorter when more keystrokes were primed in sequence in Experiment 4.

Lashley (1951) identified three problems that challenge classic chaining theories as viable means of controlling serial order. One problem is that skilled keystrokes are executed too rapidly for afferent information from each keystroke to serve as the stimulus for the next keystroke (Keele, 1968; Lashley, 1951). However, keystrokes can be executed rapidly if the motor command for each keystroke serves as the stimulus for the next keystroke, as modern chaining theories suggest (Desmurget \& Grafton, 2000). Another problem is that items should never be produced out of order (i.e., transpositions), because each item cues the next item in the sequence. However, items can be produced out of order if compound associations link all items in a sequence to the prior context, as modern chaining theories suggest (Botvinick \& Plaut, 2004, 2006; Chance \& Kahana, 1997; Keele et al., 2003; Murdock, 1993; Yamashita \& Tani, 2008).

A third problem is that classic chaining theories do not account for recovery from errors. Each item cues the next item in a sequence, so a transposition, omission, or insertion error would not cue the right item. Modern chaining theories can be extended to account for recovery from errors if we assume the cognitive system reinstates the prior context and works back through the chain. Skilled typists prefer to correct errors, moving automatically to press the backspace key (Crump \& Logan, 2013), deleting back to the error or deleting the entire word. Both strategies reset the context, and provide cues that retrieve the right sequence.

\section{Serial Order by Position Coding}

Classic position coding theories do not account for our findings. Position coding theories assume that keystroke identity and order

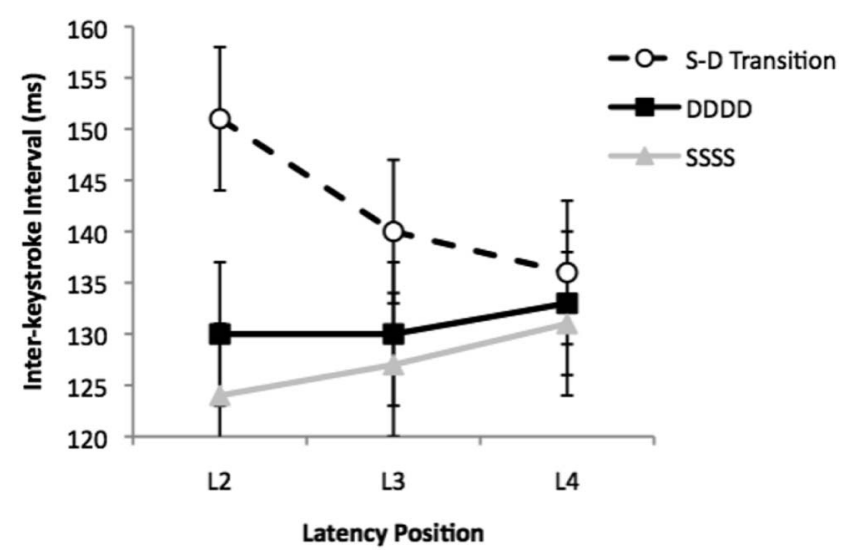

Figure 9. Average interkeystroke latencies for SSSS, DDDD, and S-D transition (i.e., SDDD L2, SSDD L3, and SSSD L4). Error bars display Fisher's least significant difference for $p<.05$. 
are represented separately. Preparing a motor program requires activating keystroke identities and associating them with position codes or slots. This predicts a benefit of priming the appropriate identities in an inappropriate order. We should expect priming from anagrams and from the middle and last letters of words, but we found no such priming in Experiments 1 through 3. Modern, position coding theories that incorporate primacy gradients (Brown et al., 2000; Bullock, \& Rhodes, 2003; Burgess \& Hitch, 1999; Grossberg, 1978; Hartley \& Houghton, 1996; Marshuetz, 2005; Page \& Norris, 1998; Rhodes et al., 2004) may be better able to account for our results than their classic predecessors, but they still predict nonzero priming for anagrams, and for keystrokes in the middle and last positions of words, which we did not find. Thus, the results seem more consistent with chaining.

\section{The Problem of Serial Order: One Problem or Many?}

The overarching purpose of our study was to test the generality of the conclusion, drawn from studies of serial recall and speech, that the problem of serial order is solved by position coding. We found that this conclusion does not generalize to typing. Our results suggest that the problem of serial order in typing is controlled by serial chaining. Thus, the cognitive system appears to solve different problems of serial order in different ways.

The different solutions seem tailored to the demands of the tasks. Serial recall tasks are prone to both item and order errors, so recovery from errors is an important problem. The cognitive system may prefer position coding because it makes recovery from errors easier. By contrast, typing is very accurate and recovery from errors is easy-press the delete key to erase the error, then start over-so recovery from errors is less of a problem (Crump \& Logan, 2013). Typing tasks usually present familiar words that have been typed many times before. Each repetition strengthens sequential associations between keystrokes, forming a chain. The cognitive system may prefer serial chaining for skilled typing because the sequential associations speed typing. By contrast, serial recall tasks present new unstructured lists on each trial. There is no repetition of the sequence that would produce chaining, so there is no reason for the cognitive system to prefer it over position coding, which allows rapid recovery from errors.

We might expect speech to be like typing because it is also fast and the materials are familiar words. However, speech differs from typing in two ways that might favor different solutions to the problem of serial order. First, speech is much faster than typing. People speak approximately 150 WPM, producing about 660 phonemes per minute (Levelt, 1999). Typists type approximately 75 WPM, producing about 375 keystrokes per minute. Chaining may be fast enough for typing - the efference copy of one command may be the stimulus for generating the next command-but it may not be fast enough for the high rates of speech. Lashley (1951) suggested hierarchical control could overcome the speed constraint, and position coding is hierarchical, representing order at one level and items at another. Consistent with this speculation, Yamaguchi, Crump, and Logan (2013) pressed typists to trade accuracy for speed, and found that typists seemed unable to type faster than $100 \mathrm{~ms}$ per keystroke. Serial chaining may not support faster responding, and that may invite the control system to consider position coding as a way around this limit. However, the 18to 20-year-old typists we tested had a lot less practice typing than speaking. They started typing around 10 years old (Logan \& Crump, 2011), but begin speaking at 1 year. This doubling of the amount of practice may be responsible for speech being faster. We may see a transition from position coding when the response is so unfamiliar it must be maintained in STM, to serial chaining at intermediate levels of practice when sequential associations are available to support performance, to position coding at high levels of skill when serial chaining is not fast enough to support the desired level of performance.

Second, speech is more complex than typing. Speech contains units at three hierarchical levels-words, syllables, and phonemes-and this may invite position coding (Dell, 1986, 1990; Levelt, 1989; Mackay, 1987; O’Seaghdha \& Marin, 2000; Sevald, \& Dell, 1994; Stemberger, 1985, 1990). Syllabic structure is important in speech because it organizes articulation and, at the same time, expresses pragmatics through prosody. The order of syllables may be represented by position codes within words, and the order of phonemes may be represented by position codes within syllables. By contrast, typing contains units at two hierarchical levels-words and letters. Syllables are not important in the motor component of typing (Gentner, Larochelle, \& Grudin, 1988), and the mapping from phonemes to graphemes is only partially consistent (in English). Words activate keystrokes directly (Crump \& Logan, 2010; Logan \& Crump, 2011). The cognitive system may prefer to use position coding to represent the more complex structure in spoken words, and serial chaining to represent the less complex structure in typed words (Keele et al., 2003).

\section{Concluding Remarks}

Different tasks pose different problems of serial order. Previous research showed that problems of serial order in serial recall and speech were solved by position coding, which suggested that all problems of serial order may be solved by position coding. Our experiments tested the generality of this conclusion in skilled typing by adapting a priming procedure that varied the overlap between primes and targets. We found consistent evidence for serial chaining, which suggests that the cognitive system can solve different problems of serial order in different ways.

\section{References}

Botvinick, M., \& Plaut, D. C. (2004). Doing without schema hierarchies: A recurrent connectionist approach to normal and impaired routine sequential action. Psychological Review, 111, 395-429. doi:10.1037/ 0033-295X.111.2.395

Botvinick, M. M., \& Plaut, D. C. (2006). Short-term memory for serial order: A recurrent neural network model. Psychological Review, 113, 201-233. doi:10.1037/0033-295X.113.2.201

Brown, G. D. A., Preece, T., \& Hulme, C. (2000). Oscillator-based memory for serial order. Psychological Review, 107, 127-181. doi:10.1037/ 0033-295X.107.1.127

Bullock, D., \& Rhodes, B. J. (2003). Competitive queuing for planning and serial performance. In M. A. Arbib (Ed.), The handbook of brain theory and neural networks (2nd ed., pp. 241-244). Cambridge, MA: MIT Press.

Burgess, N., \& Hitch, G. J. (1999). Memory for serial order: A network model of the phonological loop and its timing. Psychological Review, 106, 551-581. doi:10.1037/0033-295X.106.3.551

Chance, F. S., \& Kahana, M. J. (1997). Testing the role of associative 
interference and compound cues in sequence memory. In J. Bower (Ed.), Computational neuroscience, trends in research (pp. 599-603). New York, NY: Plenum Press. doi:10.1007/978-1-4757-9800-5_93

Conrad, R. (1965). Order error in immediate recall of sequences. Journal of Verbal Learning \& Verbal Behavior, 4, 161-169. doi:10.1016/S00225371(65)80015-9

Crossman, E. R. F. W. (1961). Information and serial order in human immediate memory. In C. Cherry (Ed.), Information theory (pp. 147159). Lon, UK: Butterworths.

Crowder, R. G. (1982). Demise of short-term memory. Acta Psychologica, 50, 291-323. doi:10.1016/0001-6918(82)90044-0

Crump, M. J. C., \& Logan, G. D. (2010). Hierarchical control and skilled typing: Evidence for word level control over the execution of individual keystrokes. Journal of Experimental Psychology: Learning, Memory, and Cognition, 36, 1369-1380. doi:10.1037/a0020696

Crump, M. J. C., \& Logan, G. D. (2013). Prevention and correction in post-error performance: An ounce of prevention and a pound of cure. Journal of Experimental Psychology: General, 142, 692-709. doi: 10.1037/a0030014

Davies, M. (2008). The corpus of contemporary American English (COCA): 410+ million words, 1990-present. Retrieved from http:// www.americancorpus.org

Dell, G. S. (1986). A spreading activation theory of retrieval in language production. Psychological Review, 93, 283-321. doi:10.1037/0033295X.93.3.283

Dell, G. S. (1990). Effects of frequency and vocabulary type on phonological speech errors. Language and Cognitive Processes, 5, 313-349. doi:10.1080/01690969008407066

Desmurget, M., \& Grafton, S. (2000). Forward modeling allows feedback control for fast reaching movements. Trends in Cognitive Sciences, 4, 423-431. doi:10.1016/S1364-6613(00)01537-0

Estes, W. K. (1972). An associative basis for coding and organization in memory. In A. W. Melton \& E. Martin (Eds.), Coding processes in human memory (pp. 161-190). Washington, DC: Winston.

Gentner, D. R., Larochelle, S., \& Grudin, J. (1988). Lexical, sublexical, and peripheral effects in skilled typewriting. Cognitive Psychology, 20, 524-548. doi:10.1016/0010-0285(88)90015-1

Glenberg, A. M., \& Swanson, N. G. (1986). A temporal distinctiveness theory of recency and modality effects. Journal of Experimental Psychology: Learning, Memory, and Cognition, 12, 3-15. doi:10.1037/ 0278-7393.12.1.3

Grossberg, S. (1978). A theory of human memory: Self-organization and performance of sensory-motor codes, maps, and plans. In R. Rosen \& F. Snell (Eds.), Progress in theoretical biology (Vol. 5, pp. 233-374). New York, NY: Academic Press. doi:10.1016/B978-0-12-543105-7.50013-0

Hartley, T. A., \& Houghton, G. (1996). A linguistically constrained model of short-term memory for nonwords. Journal of Memory and Language, 35, 1-31. doi:10.1006/jmla.1996.0001

Healy, A. F. (1974). Separating item from order information in short-term memory. Journal of Verbal Learning \& Verbal Behavior, 13, 644-655. doi:10.1016/S0022-5371(74)80052-6

Henson, R. N. A. (1998). Short-term memory for serial order: The start-end model. Cognitive Psychology, 36, 73-137. doi:10.1006/cogp.1998.0685

Keele, S. W. (1968). Movement control in skilled motor performance. Psychological Bulletin, 70, 387-403. doi:10.1037/h0026739

Keele, S. W., Cohen, A., \& Ivry, R. B. (1990). Motor programs: Concepts and issues. In M. Jennerod (Ed.), Attention \& performance XIII: Motor representation and control (pp. 77-110). Hillsdale, NJ: Erlbaum.

Keele, S. W., Ivry, R. B., Mayr, U., Hazeltine, E., \& Heuer, H. (2003). The cognitive and neural architecture of sequence representation. Psychological Review, 110, 316-339. doi:10.1037/0033-295X.110.2.316

Lashley, K. S. (1951). The problem of serial order. In L. A. Jeffress (Ed.), Cerebral mechanisms in behavior (pp. 112-136). New York, NY: Wiley.
Lee, C. L., \& Estes, W. K. (1977). Order and position in primary memory for letter strings. Journal of Verbal Learning \& Verbal Behavior, 16, 395-418. doi:10.1016/S0022-5371(77)80036-4

Lee, C. L., \& Estes, W. K. (1981). Item and order information in short-term memory: Evidence for multilevel perturbation processes. Journal of Experimental Psychology: Human Learning and Memory, 7, 149-169. doi:10.1037/0278-7393.7.3.149

Levelt, W. J. M. (1989). Speaking: From intention to articulation. Cambridge, MA: MIT Press.

Levelt, W. J. M. (1999). Models of word production. Trends in Cognitive Sciences, 3, 223-232. doi:10.1016/S1364-6613(99)01319-4

Logan, G. D., \& Crump, M. J. C. (2011). Hierarchical control of cognitive processes: The case for skilled typewriting. In B. H. Ross (Ed.), The psychology of learning and motivation (Vol. 54, pp. 1-27). Burlington, MA: Academic Press.

Logan, G. D., \& Zbrodoff, N. J. (1998). Stroop type interference: Congruity effects in color naming with typewritten responses. Journal of Experimental Psychology: Human Perception and Performance, 24, 978 992. doi:10.1037/0096-1523.24.3.978

Mackay, D. G. (1987). The organization of perception and action: A theory for language and other cognitive skills. New York, NY: Springer. doi:10.1007/978-1-4612-4754-8

Marshuetz, C. (2005). Order information in working memory: An integrative review of evidence from brain and behavior. Psychological Bulletin 131, 323-339. doi:10.1037/0033-2909.131.3.323

Melton, A. W., \& Irwin, J. M. (1940). The influence of degree of interpolated learning on retroactive inhibition and the overt transfer of specific responses. The American Journal of Psychology, 53, 173-203. doi: $10.2307 / 1417415$

Miller, G. A., Galanter, E., \& Pribram, K. H. (1960). Plans and the structure of behavior. New York, NY: Henry Holt. doi:10.1037/10039000

Murdock, B. B. (1960). The immediate retention of unrelated words. Journal of Experimental Psychology, 60, 222-234. doi:10.1037/ h0045145

Murdock, B. B. (1983). A distributed memory model for serial-order information. Psychological Review, 90, 316-338. doi:10.1037/0033295X.90.4.316

Murdock, B. B. (1993). TODAM2: A model for the storage and retrieval of item, associative, and serial order information. Psychological Review, 100, 183-203. doi:10.1037/0033-295X.100.2.183

Neill, W. T., \& Mathis, K. M. (1998). Transfer-inappropriate processing: Negative priming and related phenomena. In D. L. Medin (Ed.), The psychology of learning and motivation: Advances in research and theory (Vol. 38, pp. 1-44). San Diego, CA: Academic Press. doi:10.1016/ S0079-7421(08)60182-6

Neill, W. T., Valdes, L. A., Terry, K. M., \& Gorfein, D. S. (1992). Persistence of negative priming: II. Evidence for episodic trace retrieval Journal of Experimental Psychology: Learning, Memory, and Cognition, 18, 993-1000. doi:10.1037/0278-7393.18.5.993

O'Seaghdha, P., \& Marin, J. W. (2000). Phonological competition and nonsequential processes in word production. Journal of Experimental Psychology: Human Perception and Performance, 26, 57-73.

Page, M. P. A., \& Norris, D. (1998). The primacy model: A new model of immediate serial recall. Psychological Review, 105, 761-781. doi: 10.1037/0033-295X.105.4.761-781

Peressotti, F., \& Grainger, J. (1999). The role of letter identity and letter priming in orthographic priming. Perception \& Psychophysics, 61, 691706. doi:10.3758/BF03205539

Rhodes, B. J., Bullock, D., Verwey, W. B., Averbeck, B. B., \& Page, M. P. A. (2004). Learning and production of movement sequences: Behavioral, neurophysiological, and modeling perspectives. Human Movement Science, 23, 699-746. doi:10.1016/j.humov.2004.10.008 
Rosenbaum, D. A., Cohen, R. G., Jax, S. A., Weiss, D. J., \& van der Wel, R. (2007). The problem of serial order in behavior: Lashley's legacy. Human Movement Science, 26, 525-554. doi:10.1016/j.humov.2007.04.001

Rosenbaum, D. A., Engelbrecht, S. E., Bushe, M. M., \& Loukopoulos, L. D. (1993). Knowledge model for selecting and producing reaching movements. Journal of Motor Behavior, 25, 217-227. doi:10.1080/ 00222895.1993.9942051

Rosenbaum, D. A., Hindorff, D. A., \& Munro, E. M. (1987). Scheduling and programming of rapid finger sequences: Tests and elaborations of the hierarchical editor model. Journal of Experimental Psychology: Human Perception and Performance, 13, 193-203. doi:10.1037/00961523.13.2.193

Salthouse, T. A. (1986). Perceptual, cognitive, and motoric aspects of transcription typing. Psychological Bulletin, 99, 303-319.

Sevald, C. S., \& Dell, G. S. (1994). The sequential cuing effect in speech production. Cognition, 53, 91-127.

Stemberger, J. P. (1985). An interactive activation model of language production. In W. W. Ellis (Ed.), Progress in the psychology of language (Vol. 1, pp.143-186). Hillsdale, NJ: Erlbaum.

Stemberger, J. P. (1990). Wordshape errors in language production. Cognition, 35, 123-157. doi:10.1016/0010-0277(90)90012-9
Van Selst, M., \& Jolicoeur, P. (1994). A solution to the effect of sample size on outlier elimination. The Quarterly Journal of Experimental Psychology A: Human Experimental Psychology, 47, 631-650. doi: 10.1080/14640749408401131

Washburn, M. F. (1916). Movement and mental imagery: Outlines of a motor theory of the complexer mental processes. Boston, MA: Houghton Mifflin Company. doi:10.1037/11575-000

Wickelgren, W. A. (1965). Distinctive features and errors in short-term memory for English vowels. Journal of Acoustical Society of America, 39, 388-398. doi:10.1121/1.1909900

Wilson, M. (1987). MRC psycholinguistic database: Machine usable dictionary (Version 2.00). Retrieved from http://www.psy.uwa.edu.au/ mrcdatabase/uwa mrc.htm

Yamaguchi, M., Crump, M. J. C., \& Logan, G. D. (2013). Speed-accuracy trade-off in skilled typewriting: Decomposing the contributions of hierarchical control loops. Journal of Experimental Psychology: Human Perception and Performance, 39, 678-699. doi:10.1037/a0030512

Yamashita, Y., \& Tani, J. (2008). Emergence of functional hierarchy in a multiple timescale neural network model: A humanoid robot experiment. PLoS Computational Biology, 4, e1000220. doi:10.1371/journal.pcbi.1000220 
Appendix A

Target Words Used in Experiment 1 Displayed as Anagram Pairs

\begin{tabular}{|c|c|c|}
\hline & Target & Anagram \\
\hline 1 & ADORN & RADON \\
\hline 2 & AGREE & EAGER \\
\hline 3 & ALERT & LATER \\
\hline 4 & ALLOY & LOYAL \\
\hline 5 & ALOFT & FLOAT \\
\hline 6 & AMBER & BREAM \\
\hline 7 & AMBLE & BLAME \\
\hline 8 & AMPLE & MAPLE \\
\hline 9 & ANGER & RANGE \\
\hline 10 & ATTIC & TACIT \\
\hline 11 & BELOW & ELBOW \\
\hline 12 & BLEAT & TABLE \\
\hline 13 & BRAID & RABID \\
\hline 14 & BROTH & THROB \\
\hline 15 & BRUSH & SHRUB \\
\hline 16 & BUDGE & DEBUG \\
\hline 17 & CANOE & OCEAN \\
\hline 18 & CHARM & MARCH \\
\hline 19 & CHEAP & PEACH \\
\hline 20 & CHEAT & TEACH \\
\hline 21 & CLASP & SCALP \\
\hline 22 & CLEAN & LANCE \\
\hline 23 & CRUEL & ULCER \\
\hline 24 & DICER & CRIED \\
\hline 25 & DOZEN & ZONED \\
\hline 26 & DUSTY & STUDY \\
\hline 27 & EARNS & SNARE \\
\hline 28 & EARTH & HEART \\
\hline 29 & EASEL & LEASE \\
\hline 30 & EQUIP & PIQUE \\
\hline 31 & FIBER & BRIEF \\
\hline 32 & FLESH & SHELF \\
\hline 33 & FLIER & RIFLE \\
\hline 34 & GABLE & BAGLE \\
\hline 35 & GIRTH & RIGHT \\
\hline 36 & GROWN & WRONG \\
\hline 37 & GULPS & PLUGS \\
\hline 38 & HATED & DEATH \\
\hline 39 & HORSE & SHORE \\
\hline 40 & HOSES & SHOES \\
\hline 41 & IDEAS & AIDES \\
\hline 42 & INFER & FINER \\
\hline 43 & INURE & URINE \\
\hline 44 & ITEMS & MITES \\
\hline 45 & LAPSE & PEALS \\
\hline 46 & LAYER & EARLY \\
\hline 47 & LEASH & SHALE \\
\hline 48 & LEAST & SLATE \\
\hline 49 & LEMON & MELON \\
\hline 50 & MANOR & ROMAN \\
\hline 51 & MAYBE & BEAMY \\
\hline 52 & MEDAL & LAMED \\
\hline 53 & MERIT & TIMER \\
\hline 54 & MOIST & OMITS \\
\hline 55 & NAKED & KNEAD \\
\hline 56 & NAMES & MEANS \\
\hline 57 & NEEDS & DENSE \\
\hline 58 & NIGHT & THING \\
\hline
\end{tabular}


Appendix A (continued)

\begin{tabular}{|c|c|c|}
\hline & Target & Anagram \\
\hline 59 & NORTH & THORN \\
\hline 60 & ONSET & STONE \\
\hline 61 & ORGAN & GROAN \\
\hline 62 & OUTER & ROUTE \\
\hline 63 & PASTE & SPATE \\
\hline 64 & PETAL & LEAPT \\
\hline 65 & PHASE & SHAPE \\
\hline 66 & POSTS & STOPS \\
\hline 67 & PROSE & SPORE \\
\hline 68 & PURSE & SUPER \\
\hline 69 & RAISE & ARIES \\
\hline 70 & RINSE & SIREN \\
\hline 71 & ROBED & BORED \\
\hline 72 & ROPES & PORES \\
\hline 73 & RUNTS & TURNS \\
\hline 74 & SCARE & ACRES \\
\hline 75 & SERVE & VERSE \\
\hline 76 & SHARE & HEARS \\
\hline 77 & SLEPT & PELTS \\
\hline 78 & SLIME & MILES \\
\hline 79 & STAGE & GATES \\
\hline 80 & STEAM & MATES \\
\hline 81 & STRAP & PARTS \\
\hline 82 & SWEAR & WARES \\
\hline 83 & SWEAT & WASTE \\
\hline 84 & TACOS & COATS \\
\hline 85 & TAKES & STEAK \\
\hline 86 & TASTE & STATE \\
\hline 87 & THROW & WORTH \\
\hline 88 & TOWER & WROTE \\
\hline 89 & TRADE & DATER \\
\hline 90 & TRAMS & SMART \\
\hline 91 & VEILS & LIVES \\
\hline 92 & VOTER & OVERT \\
\hline 93 & VOTES & STOVE \\
\hline 94 & WADES & SAWED \\
\hline 95 & WARTS & STRAW \\
\hline 96 & WORDY & DOWRY \\
\hline 97 & ZEBRA & BRAZE \\
\hline
\end{tabular}

(Appendices continue) 


\section{Appendix B}

Target Words and Paired SSDD, DDSS, and DDDD Primes Used in Experiment 2

\begin{tabular}{|c|c|c|c|c|}
\hline & Target & SSDD & DDSS & DDDD \\
\hline 1 & BANG & BASE & WING & WOVE \\
\hline 2 & BASE & BANG & WISE & WORD \\
\hline 3 & BLOT & BLUR & SPOT & WARM \\
\hline 4 & BLUR & BLOT & SPUR & WAND \\
\hline 5 & BOAR & BOLT & FEAR & SUIT \\
\hline 6 & BOLT & BOAR & FELT & WARE \\
\hline 7 & BURN & BUSY & EARN & SOAK \\
\hline 8 & BUSY & BURN & EASY & WAIT \\
\hline 9 & CALM & CASH & FILM & VOTE \\
\hline 10 & CASH & CALM & FISH & VOID \\
\hline 11 & CHAP & CHOW & SLAP & TOWN \\
\hline 12 & CHOW & CHAP & SLOW & SEAT \\
\hline 13 & COAL & CORK & PEAL & TINY \\
\hline 14 & CORK & COAL & PERK & PLAN \\
\hline 15 & CRAB & CROP & STAB & SPOT \\
\hline 16 & CROP & CRAB & STOP & TAME \\
\hline 17 & DECK & DENY & TICK & PART \\
\hline 18 & DENY & DECK & TINY & FAST \\
\hline 19 & DIME & DISK & TAME & TASK \\
\hline 20 & DISK & DIME & TASK & PEAL \\
\hline 21 & DRAG & DRIP & FLAG & STOP \\
\hline 22 & DRIP & DRAG & FLIP & STAB \\
\hline 23 & DUKE & DUMP & RAKE & SWAY \\
\hline 24 & DUMP & DUKE & RAMP & GRAY \\
\hline 25 & EARN & EASY & BURN & SOFT \\
\hline 26 & EASY & EARN & BUSY & ROUT \\
\hline 27 & FACE & FAST & MICE & SLOW \\
\hline 28 & FAST & FACE & MIST & DENY \\
\hline 29 & FEAR & FELT & BOAR & SHUT \\
\hline 30 & FELT & FEAR & BOLT & SHAM \\
\hline 31 & FILM & FISH & CALM & SANK \\
\hline 32 & FISH & FILM & CASH & ROAM \\
\hline 33 & FLAG & FLIP & DRAG & SPUR \\
\hline 34 & FLIP & FLAG & DRIP & SCAN \\
\hline 35 & FOND & FORM & WAND & RAMP \\
\hline 36 & FORM & FOND & WARM & SALE \\
\hline 37 & GOAT & GOLF & SEAT & MICE \\
\hline 38 & GOLF & GOAT & SELF & RAKE \\
\hline 39 & GRAY & GRIM & SWAY & DUMP \\
\hline 40 & GRIM & GRAY & SWIM & SLAP \\
\hline 41 & HARD & HAVE & WORD & PLUM \\
\hline 42 & HAVE & HARD & WOVE & TOMB \\
\hline 43 & HUGE & HURT & PAGE & TICK \\
\hline 44 & HURT & HUGE & PART & WISE \\
\hline 45 & LAMB & LAWN & TOMB & PERK \\
\hline 46 & LAWN & LAMB & TOWN & SURE \\
\hline 47 & LEAK & LEFT & SOAK & MIST \\
\hline 48 & LEFT & LEAK & SOFT & MAID \\
\hline 49 & MAID & MATE & VOID & LEFT \\
\hline 50 & MATE & MAID & VOTE & PINK \\
\hline 51 & MICE & MIST & FACE & GOAT \\
\hline 52 & MIST & MICE & FAST & LEAK \\
\hline 53 & PAGE & PART & HUGE & SWIM \\
\hline 54 & PART & PAGE & HURT & DECK \\
\hline 55 & PEAL & PERK & COAL & DISK \\
\hline 56 & PERK & PEAL & CORK & LAMB \\
\hline 57 & PILE & PINK & SALE & SCUM \\
\hline 58 & PINK & PILE & SANK & MATE \\
\hline
\end{tabular}


Appendix B (continued)

\begin{tabular}{|c|c|c|c|c|}
\hline & Target & SSDD & DDSS & DDDD \\
\hline 59 & PLAN & PLUM & SCAN & CORK \\
\hline 60 & PLUM & PLAN & SCUM & HARD \\
\hline 61 & RAKE & RAMP & DUKE & GOLF \\
\hline 62 & RAMP & RAKE & DUMP & FOND \\
\hline 63 & ROAM & ROUT & SHAM & FISH \\
\hline 64 & ROUT & ROAM & SHUT & EASY \\
\hline 65 & SALE & SANK & PILE & FORM \\
\hline 66 & SANK & SALE & PINK & FILM \\
\hline 67 & SCAN & SCUM & PLAN & FLIP \\
\hline 68 & SCUM & SCAN & PLUM & PILE \\
\hline 69 & SEAT & SELF & GOAT & CHOW \\
\hline 70 & SELF & SEAT & GOLF & WING \\
\hline 71 & SHAM & SHUT & ROAM & FELT \\
\hline 72 & SHUT & SHAM & ROUT & FEAR \\
\hline 73 & SLAP & SLOW & CHAP & GRIM \\
\hline 74 & SLOW & SLAP & CHOW & FACE \\
\hline 75 & SOAK & SOFT & LEAK & BURN \\
\hline 76 & SOFT & SOAK & LEFT & EARN \\
\hline 77 & SPOT & SPUR & BLOT & CRAB \\
\hline 78 & SPUR & SPOT & BLUR & FLAG \\
\hline 79 & STAB & STOP & CRAB & DRIP \\
\hline 80 & STOP & STAB & CROP & DRAG \\
\hline 81 & SUIT & SURE & WAIT & BOAR \\
\hline 82 & SURE & SUIT & WARE & LAWN \\
\hline 83 & SWAY & SWIM & GRAY & DUKE \\
\hline 84 & SWIM & SWAY & GRIM & PAGE \\
\hline 85 & TAME & TASK & DIME & CROP \\
\hline 86 & TASK & TAME & DISK & DIME \\
\hline 87 & TICK & TINY & DECK & HUGE \\
\hline 88 & TINY & TICK & DENY & COAL \\
\hline 89 & TOMB & TOWN & LAMB & HAVE \\
\hline 90 & TOWN & TOMB & LAWN & CHAP \\
\hline 91 & VOID & VOTE & MAID & CASH \\
\hline 92 & VOTE & VOID & MATE & CALM \\
\hline 93 & WAIT & WARE & SUIT & BUSY \\
\hline 94 & WAND & WARM & FOND & BLUR \\
\hline 95 & WARE & WAIT & SURE & BOLT \\
\hline 96 & WARM & WAND & FORM & BLOT \\
\hline 97 & WING & WISE & BANG & SELF \\
\hline 98 & WISE & WING & BASE & HURT \\
\hline 99 & WORD & WOVE & HARD & BASE \\
\hline 100 & WOVE & WORD & HAVE & BANG \\
\hline
\end{tabular}

(Appendices continue) 
Appendix C

Target Words and Paired SDDS, DSSD, and DDDD Primes Used in Experiment 3

\begin{tabular}{|c|c|c|c|c|}
\hline & Target & SDDS & DSSD & DDDD \\
\hline 1 & BAIT & BELT & HAIR & MUCH \\
\hline 2 & BANK & BULK & LAND & ROSE \\
\hline 3 & BATH & BUSH & GATE & WORE \\
\hline 4 & BEAR & BLUR & MEAK & WHIM \\
\hline 5 & BELT & BAIT & SELF & GOWN \\
\hline 6 & BLOW & BREW & PLOT & TUNE \\
\hline 7 & BLUR & BEAR & GLUE & WIFE \\
\hline 8 & BOND & BRAD & PONY & HAUL \\
\hline 9 & BRAD & BOND & TRAY & CLIP \\
\hline 10 & BREW & BLOW & FRET & TIDY \\
\hline 11 & BULK & BANK & MULE & RIDE \\
\hline 12 & BUSH & BATH & FUSE & VENT \\
\hline 13 & CALF & CHEF & SALT & PONY \\
\hline 14 & CASE & CUTE & TASK & JUNK \\
\hline 15 & CHAP & CLIP & SHAM & FIST \\
\hline 16 & CHEF & CALF & WHEY & LAND \\
\hline 17 & CHIN & CORN & WHIM & LARK \\
\hline 18 & CITY & COPY & SITE & HOWL \\
\hline 19 & CLIP & CHAP & SLIM & BRAD \\
\hline 20 & COLD & CURD & VOLT & PIES \\
\hline 21 & COPY & CITY & MOPE & SELF \\
\hline 22 & CORN & CHIN & SORT & LIFT \\
\hline 23 & CURD & COLD & SURF & LOST \\
\hline 24 & CUTE & CASE & DUTY & GRIN \\
\hline 25 & DAMP & DRIP & TAME & FERN \\
\hline 26 & DENY & DUTY & VENT & LICK \\
\hline 27 & DRIP & DAMP & GRIN & FAUN \\
\hline 28 & DUTY & DENY & CUTE & LAWN \\
\hline 29 & FAUN & FERN & HAUL & DRIP \\
\hline 30 & FERN & FAUN & JERK & DAMP \\
\hline 31 & FILM & FOAM & SILK & TASK \\
\hline 32 & FIRE & FUSE & GIRL & TUCK \\
\hline 33 & FIST & FRET & RISE & CHAP \\
\hline 34 & FLAT & FORT & PLAY & JERK \\
\hline 35 & FOAM & FILM & GOAL & SITE \\
\hline 36 & FORT & FLAT & WORE & LIEN \\
\hline 37 & FRET & FIST & BREW & SILK \\
\hline 38 & FUSE & FIRE & BUSH & TRAY \\
\hline 39 & GATE & GLUE & BATH & SLIM \\
\hline 40 & GIRL & GOAL & FIRE & TAME \\
\hline 41 & GLUE & GATE & BLUR & WAVY \\
\hline 42 & GOAL & GIRL & FOAM & SURF \\
\hline 43 & GOWN & GRIN & HOWL & BELT \\
\hline 44 & GRIN & GOWN & DRIP & CUTE \\
\hline 45 & HAIR & HOUR & BAIT & NOTE \\
\hline 46 & HAUL & HOWL & FAUN & BOND \\
\hline 47 & HOUR & HAIR & LOUD & SAVE \\
\hline 48 & HOWL & HAUL & GOWN & CITY \\
\hline 49 & JERK & JUNK & FERN & FLAT \\
\hline 50 & JUNK & JERK & TUNE & CASE \\
\hline 51 & LAND & LOUD & BANK & CHEF \\
\hline 52 & LARK & LICK & WARM & CHIN \\
\hline 53 & LAWN & LIEN & PAWS & DUTY \\
\hline 54 & LICK & LARK & NICE & DENY \\
\hline 55 & LIEN & LAWN & PIES & FORT \\
\hline 56 & LIFT & LOST & WIFE & CORN \\
\hline 57 & LOST & LIFT & ROSE & CURD \\
\hline 58 & LOUD & LAND & HOUR & SHAM \\
\hline
\end{tabular}


Appendix C (continued)

\begin{tabular}{|c|c|c|c|c|}
\hline & Target & SDDS & DSSD & DDDD \\
\hline 59 & MEAK & MINK & BEAR & VOLT \\
\hline 60 & MINK & MEAK & PINT & WHEY \\
\hline 61 & MOPE & MULE & COPY & SALT \\
\hline 62 & МOTH & $\mathrm{MUCH}$ & NOTE & RACE \\
\hline 63 & MUCH & MOTH & TUCK & BAIT \\
\hline 64 & MULE & MOPE & BULK & PAWS \\
\hline 65 & NICE & NOTE & LICK & SORT \\
\hline 66 & NOTE & NICE & MOTH & HAIR \\
\hline 67 & PAWS & PIES & LAWN & MULE \\
\hline 68 & PIES & PAWS & LIEN & COLD \\
\hline 69 & PINT & PLOT & MINK & WARM \\
\hline 70 & PLAY & PONY & FLAT & RISE \\
\hline 71 & PLOT & PINT & BLOW & SACK \\
\hline 72 & PONY & PLAY & BOND & CALF \\
\hline 73 & RACE & RISE & SACK & MOTH \\
\hline 74 & RIDE & ROSE & TIDY & BULK \\
\hline 75 & RISE & RACE & FIST & PLAY \\
\hline 76 & ROSE & RIDE & LOST & BANK \\
\hline 77 & SACK & SILK & RACE & PLOT \\
\hline 78 & SALT & SORT & CALF & MOPE \\
\hline 79 & SAVE & SITE & WAVY & HOUR \\
\hline 80 & SELF & SURF & BELT & COPY \\
\hline 81 & SHAM & SLIM & CHAP & LOUD \\
\hline 82 & SILK & SACK & FILM & FRET \\
\hline 83 & SITE & SAVE & CITY & FOAM \\
\hline 84 & SLIM & SHAM & CLIP & GATE \\
\hline 85 & SORT & SALT & CORN & NICE \\
\hline 86 & SURF & SELF & CURD & GOAL \\
\hline 87 & TAME & TUNE & DAMP & GIRL \\
\hline 88 & TASK & TUCK & CASE & FILM \\
\hline 89 & TIDY & TRAY & RIDE & BREW \\
\hline 90 & TRAY & TIDY & BRAD & FUSE \\
\hline 91 & TUCK & TASK & MUCH & FIRE \\
\hline 92 & TUNE & TAME & JUNK & BLOW \\
\hline 93 & VENT & VOLT & DENY & BUSH \\
\hline 94 & VOLT & VENT & COLD & MEAK \\
\hline 95 & WARM & WHIM & LARK & PINT \\
\hline 96 & WAVY & WHEY & SAVE & GLUE \\
\hline 97 & WHEY & WAVY & CHEF & MINK \\
\hline 98 & WHIM & WARM & CHIN & BEAR \\
\hline 99 & WIFE & WORE & LIFT & BLUR \\
\hline 100 & WORE & WIFE & FORT & BATH \\
\hline
\end{tabular}

(Appendices continue) 


\section{Appendix D}

Target Words and Paired SSSD, SSDD, SDDD, and DDDD Primes Used in Experiment 3

\begin{tabular}{|c|c|c|c|c|c|}
\hline & Target & SSSD & SSDD & SDDD & DDDD \\
\hline 1 & BOAR & BOAT & BONE & BUSH & WHIP \\
\hline 2 & BOAT & BOAR & BOND & BURN & REND \\
\hline 3 & BOND & BONE & BOAT & BURY & SLAY \\
\hline 4 & BONE & BOND & BOAR & BUST & MILD \\
\hline 5 & BURN & BURY & BUST & BOAT & PLAY \\
\hline 6 & BURY & BURN & BUSH & BOND & SLOW \\
\hline 7 & BUSH & BUST & BURY & BOAR & TRIO \\
\hline 8 & BUST & BUSH & BURN & BONE & WARN \\
\hline 9 & CAME & CAMP & CARD & CHIP & HURT \\
\hline 10 & CAMP & CAME & CARE & CHIN & RENT \\
\hline 11 & CARD & CARE & CAME & CHEF & WHIM \\
\hline 12 & CARE & CARD & CAMP & CHEW & HUNK \\
\hline 13 & CHEF & CHEW & CHIP & CARD & TRIM \\
\hline 14 & CHEW & CHEF & CHIN & CARE & PLAN \\
\hline 15 & CHIN & CHIP & CHEW & CAMP & MANE \\
\hline 16 & CHIP & CHIN & CHEF & CAME & SNUB \\
\hline 17 & DAME & DAMP & DARK & DUET & MINT \\
\hline 18 & DAMP & DAME & DART & DUEL & SNUG \\
\hline 19 & DARK & DART & DAME & DUMB & WHEY \\
\hline 20 & DART & DARK & DAMP & DUMP & PINE \\
\hline 21 & DUEL & DUET & DUMB & DAMP & LONG \\
\hline 22 & DUET & DUEL & DUMP & DAME & SNOW \\
\hline 23 & DUMB & DUMP & DUEL & DARK & PIES \\
\hline 24 & DUMP & DUMB & DUET & DART & TRAY \\
\hline 25 & FILE & FILM & FIRM & FLAP & HAZY \\
\hline 26 & FILM & FILE & FIRE & FLAX & SNOB \\
\hline 27 & FIRE & FIRM & FILM & FLEA & LEAP \\
\hline 28 & FIRM & FIRE & FILE & FLEW & SLAB \\
\hline 29 & FLAP & FLAX & FLEW & FILE & WHEN \\
\hline 30 & FLAX & FLAP & FLEA & FILM & PIER \\
\hline 31 & FLEA & FLEW & FLAX & FIRE & GRIT \\
\hline 32 & FLEW & FLEA & FLAP & FIRM & THAN \\
\hline 33 & GRAB & GRAM & GRIN & GULF & HAIL \\
\hline 34 & GRAM & GRAB & GRIT & GULP & THEY \\
\hline 35 & GRIN & GRIT & GRAB & GUST & WASP \\
\hline 36 & GRIT & GRIN & GRAM & GUSH & FLEA \\
\hline 37 & GULF & GULP & GUSH & GRAB & TRAP \\
\hline 38 & GULP & GULF & GUST & GRAM & HAIR \\
\hline 39 & GUSH & GUST & GULF & GRIT & RANK \\
\hline 40 & GUST & GUSH & GULP & GRIN & THEM \\
\hline 41 & HAIL & HAIR & HAZE & HURT & GRAB \\
\hline 42 & HAIR & HAIL & HAZY & HUNK & GULP \\
\hline 43 & HAZE & HAZY & HAIL & HUNG & PLUM \\
\hline 44 & HAZY & HAZE & HAIR & HURL & FILE \\
\hline 45 & HUNG & HUNK & HURL & HAZE & REAP \\
\hline 46 & HUNK & HUNG & HURT & HAIR & CARE \\
\hline 47 & HURL & HURT & HUNG & HAZY & MINK \\
\hline 48 & HURT & HURL & HUNK & HAIL & CAME \\
\hline 49 & LEAF & LEAP & LENS & LONE & MAID \\
\hline 50 & LEAP & LEAF & LENT & LONG & FIRE \\
\hline 51 & LENS & LENT & LEAF & LORD & RAIL \\
\hline 52 & LENT & LENS & LEAP & LORE & WASH \\
\hline 53 & LONE & LONG & LORD & LEAF & MAIL \\
\hline 54 & LONG & LONE & LORE & LEAP & DUEL \\
\hline 55 & LORD & LORE & LONE & LENS & MANY \\
\hline 56 & LORE & LORD & LONG & LENT & RAIN \\
\hline 57 & MAID & MAIL & MANY & MINK & LEAF \\
\hline 58 & MAIL & MAID & MANE & MINT & LONE \\
\hline
\end{tabular}


Appendix D (continued)

\begin{tabular}{|c|c|c|c|c|c|}
\hline & Target & SSSD & SSDD & SDDD & DDDD \\
\hline 59 & MANE & MANY & MAIL & MILD & CHIN \\
\hline 60 & MANY & MANE & MAID & MILE & LORD \\
\hline 61 & MILD & MILE & MINT & MANE & BONE \\
\hline 62 & MILE & MILD & MINK & MANY & RANG \\
\hline 63 & MINK & MINT & MILE & MAID & HURL \\
\hline 64 & MINT & MINK & MILD & MAIL & DAME \\
\hline 65 & PIER & PIES & PINK & PLAY & FLAX \\
\hline 66 & PIES & PIER & PINE & PLAN & DUMB \\
\hline 67 & PINE & PINK & PIES & PLUM & DART \\
\hline 68 & PINK & PINE & PIER & PLUG & THAW \\
\hline 69 & PLAN & PLAY & PLUM & PIES & CHEW \\
\hline 70 & PLAY & PLAN & PLUG & PIER & BURN \\
\hline 71 & PLUG & PLUM & PLAY & PINK & REAL \\
\hline 72 & PLUM & PLUG & PLAN & PINE & HAZE \\
\hline 73 & RAIL & RAIN & RAIN & REND & LENS \\
\hline 74 & RAIN & RAIL & RAIL & RENT & LORE \\
\hline 75 & RANG & RANK & RANK & REAP & MILE \\
\hline 76 & RANK & RANG & RANG & REAL & GUSH \\
\hline 77 & REAL & REAP & REND & RANK & PLUG \\
\hline 78 & REAP & REAL & RENT & RANG & HUNG \\
\hline 79 & REND & RENT & REAP & RAIL & BOAT \\
\hline 80 & RENT & REND & REAL & RAIN & CAMP \\
\hline 81 & SLAB & SLAY & SLOW & SNOW & FIRM \\
\hline 82 & SLAY & SLAB & SLOT & SNOB & BOND \\
\hline 83 & SLOT & SLOW & SLAY & SNUG & WARM \\
\hline 84 & SLOW & SLOT & SLAB & SNUB & BURY \\
\hline 85 & SNOB & SNOW & SNUG & SLAY & FILM \\
\hline 86 & SNOW & SNOB & SNUB & SLAB & DUET \\
\hline 87 & SNUB & SNUG & SNOW & SLOW & CHIP \\
\hline 88 & SNUG & SNUB & SNOB & SLOT & DAMP \\
\hline 89 & THAN & THAW & THEM & TRIM & FLEW \\
\hline 90 & THAW & THAN & THEY & TRIO & PINK \\
\hline 91 & THEM & THEY & THAN & TRAY & GUST \\
\hline 92 & THEY & THEM & THAW & TRAP & GRAM \\
\hline 93 & TRAP & TRAY & TRIM & THEY & GULF \\
\hline 94 & TRAY & TRAP & TRIO & THEM & DUMP \\
\hline 95 & TRIM & TRIO & TRAP & THAN & CHEF \\
\hline 96 & TRIO & TRIM & TRAY & THAW & BUSH \\
\hline 97 & WARM & WARN & WASP & WHEN & SLOT \\
\hline 98 & WARN & WARM & WASH & WHIM & BUST \\
\hline 99 & WASH & WASP & WARN & WHIP & LENT \\
\hline 100 & WASP & WASH & WARM & WHEY & GRIN \\
\hline 101 & WHEN & WHEY & WHIP & WARM & FLAP \\
\hline 102 & WHEY & WHEN & WHIM & WASP & DARK \\
\hline 103 & WHIM & WHIP & WHEY & WARN & CARD \\
\hline 104 & WHIP & WHIM & WHEN & WASH & BOAR \\
\hline
\end{tabular}

Received December 18, 2013

Revision received May 14, 2014

Accepted May 15, 2014 